Aus der Klinik für Hals-, Nasen-Ohrenheilkunde

(Komm. Direktor: Prof. Dr. med. M. Canis)

im Zentrum Augenheilkunde und Hals-, Nasen-Ohrenheilkunde

der Medizinischen Fakultät der Universität Göttingen

\title{
Altersabhängige Degeneration und Lärmempfindlichkeit des Corti-Organs \\ bei tauben Otof-Knockout-Mäusen
}

\section{INAUGURAL-DISSERTATION \\ zur Erlangung des Doktorgrades}

der Medizinischen Fakultät der Georg-August-Universität zu Göttingen

\author{
vorgelegt von \\ Ursula Stalmann \\ aus
}

Oberhausen

Göttingen 2015 
Dekan:

Prof. Dr. H. K. Kroemer

I. Berichterstatter: $\quad$ Prof. Dr. T. Moser

II. Berichterstatter/in: Prof. Dr. M. Müller

III. Berichterstatter/in: Prof. Dr. M. Schön

Tag der mündlichen Prüfung: 17.06.2015 


\section{Inhaltsverzeichnis}

1 Einleitung 1

1.1 Der Gehörsinn - Anatomie und Funktion . . . . . . . . . . . . . . . . . . 1

1.2 Audiologische Diagnostik . . . . . . . . . . . . . . . 4

1.3 Erworbene Schwerhörigkeit . . . . . . . . . . . . 6

1.3.1 Lärm- und altersabhängige Schwerhörigkeit . . . . . . . . . . . 6

1.4 Angeborene Schwerhörigkeit . . . . . . . . . . . . . . 7

1.4 .1 Otoferlin ..................... 8

1.4.2 DFNB9 - eine Synaptopathie . . . . . . . . . . . . 10

1.5 Ziele der Arbeit . . . . . . . . . . . . . . . . . . . . . 11

2 Material und Methoden 12

2.1 Versuchstiere . . . . . . . . . . . . . . . . . . 12

2.2 Hörtests . . . . . . . . . . . . . . . . . . . . . . 13

2.2.1 Hirnstammaudiometrie . . . . . . . . . . . . . . . 13

2.2.2 Distorsionsprodukte otoakustischer Emissionen . . . . . . . . . . . 14

2.3 Lärmtrauma . . . . . . . . . . . . . . . . . . . . . . . 14

2.4 Histologische Untersuchung . . . . . . . . . . . . . . . 15

2.4.1 Präparation des Corti-Organs . . . . . . . . . . . . . 15

2.4 .2 Immunhistochemie . . . . . . . . . . . . . . . 16

2.5 Konfokalmikroskopie . . . . . . . . . . . . . . . . . . 18

2.5.1 Bilderfassung und -analyse . . . . . . . . . . . . . . . 19

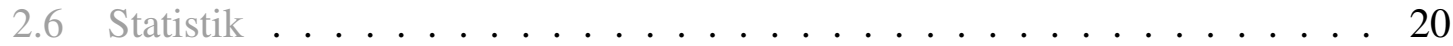

3 Ergebnisse $\quad \mathbf{2 1}$

3.1 Degeneration des Corti-Organs bei Otof-Knockout-Mäusen . . . . . . . . . 21

3.1.1 Von hochfrequent nach niedrigfrequent sich ausbreitender Funktionsverlust der äußeren Haarzellen . . . . . . . . . . . . . . 21 


\section{Inhaltsverzeichnis}

3.1.2 Langsame Degeneration von äußeren und inneren Haarzellen . . . . 24

3.2 Lärmempfindlichkeit der Otof-Knockout-Mäuse . . . . . . . . . . . . . . . 31

3.2.1 Äußere Haarzellfunktion nach Lärmtrauma . . . . . . . . . . . . . 31

3.2.2 Schweres Lärmtrauma führt zu Verlust von äußeren Haarzellen in Otof-Knockout und Otof-Wildtyp . . . . . . . . . . . . . 33

4 Diskussion 39

4.1 Frühe altersabhängige Degeneration in Abwesenheit von Otoferlin . . . . . 39

4.1.1 Einfluss der Otof-Mutation auf den Erhalt von Bändersynapsen und inneren Haarzellen . . . . . . . . . . . . . . 41

4.1.2 Degeneration von äußeren Haarzellen und Lärmempfindlichkeit . 43

4.2 Alterndes Gehör und das ahl-Allel . . . . . . . . . . . . . . . . . 45

4.2.1 Altersabhängige Synaptopathie der C57BL/6-Mauslinie . . . . . . 46

5 Zusammenfassung $\quad \mathbf{4 8}$

$\begin{array}{ll}\text { Anhang } & \mathbf{5 0}\end{array}$

Tabellenverzeichnis $\quad \mathbf{5 1}$

Abbildungsverzeichnis $\quad \mathbf{5 2}$

Literaturverzeichnis $\quad \mathbf{5 3}$

Danksagung $\quad 62$ 


\section{Einleitung}

\subsection{Der Gehörsinn - Anatomie und Funktion}

Das Gehör ist für Säugetiere eines der wichtigsten Sinnesorgane, um ihre Außenwelt wahrzunehmen und mit ihr in Kontakt zu treten. Es dient dazu, sich in ihrem Lebensraum zu orientieren und warnt vor Gefahren. Für uns Menschen ist Hören darüber hinaus unabdingbare Vorraussetzung für die Sprache, unser primäres Mittel uns mitzuteilen und mit Anderen zu kommunizieren.

Die anatomischen Strukturen des Gehörs dienen nicht allein zur Schallleitung, sondern ermöglichen die Erarbeitung weiterer Informationen. So hilft schon das Außenohr mit Ohrmuschel, Gehörgang und Trommelfell bei der Lokalisation der Schallquelle. Das Mittelohr mit der luftgefüllten Paukenhöhle beinhaltet die Gehörknöchelchenkette aus Hammer, Amboss und Steigbügel. Durch sie werden Vibrationen des Trommelfells an das Innenohr weitergeleitet. Diese Schwingungen können durch Zug von kleinen Muskeln am Trommelfell und Steigbügel (M. stapedius) in ihrer Intensität beeinflusst werden.

Der Steigbügel übt mit seiner Fußplatte Druck auf das ovale Fenster aus und erzeugt so im flüssigkeitgefüllten System der Hörschnecke Druckwellen.

Die Hörschnecke, auch Kochlea genannt, besteht aus drei parallelen, mit Lymphflüssigkeit gefüllten Röhren, die sich bei Menschen in zwei kompletten Windungen vom rundem Fenster (basal) bis zum Apex (apikal) hochschrauben. Das ovale Fenster bildet die Basis der Scala vestibuli. Am Apex ist sie am sogenannten Helicotrema mit der Scala tympani verbunden. Diese endet wiederum am runden Fenster. Zwischen diesen beiden gewundenen Röhren liegt die Scala media, durch die Reissner-Membran von der Scala vestibuli und durch die Basilarmembran von der Scala tympani getrennt. Während Scala tympani und Scala vestibuli mit Perilymphe, einem liquorähnlichen Plasmafiltrat gefüllt sind, enthält die Scala 
media kaliumreiche Endolymphe, die aus dem Kapillarnetz der Stria vaskularis sezerniert wird. Auf der Basilarmembran befindet sich der als Corti-Organ bezeichnete Verband aus inneren Haarzellen (IHZ), äußeren Haarzellen (ÄHZ) und Stützzellen.

\section{Äußere Haarzellen und kochleäre Verstärkung}

Die ÄHZ befinden sich im Corti-Organ zwischen IHZ und Stria vaskularis. Sie bilden drei Reihen von Zellkörpern entlang der gesamten Länge der Basilarmembran. Die Zellen sind epithelialen Ursprungs und spezialisiert als Sinneszellen. Jede ÄHZ trägt an ihrem apikalen Pol ein Bündel aus Stereozilien, die V förmig angeordnet sind. Die längsten Stereozilien sind im Kontakt mit der Tektorialmembran, die IHZ und ÄHZ überspannt.

ÄHZ reagieren auf Depolarisation mit einer aktiven Veränderung ihrer Länge. Diese wird durch spannungsabhängige Konformationsänderung des Membranproteins Prestin erzeugt. Elektromotilität der ÄHZ bewirkt eine Signalverstärkung, die aufgrund der tonotopen Gliederung der Kochlea frequenzspezifisch ist. Ihre aktive, nichtlineare Mechanik ist Charakteristikum der Funktion der ÄHZ als endokochleärer Verstärker und leistet einen großen Beitrag zur Sensitivität und Frequenzspezifität der IHZ entlang der Basilarmembran (Brownell et al. 1985, Dallos 1992, Liberman et al. 2002).

An ihrem basalen Pol bilden ÄHZ cholinerge Postsynapsen, die von efferenten Axonen aus dem medialen Anteil des oberen Olivenkerns (MOC) kontaktiert werden. Gleichzeitig besitzen sie auch einige wenige Bändersynapsen, mit denen sie auf postsynaptischer Seite Afferenzen von Typ II-Spiralganglienneuronen kontaktieren. Die genaue Funktion dieser afferenten und efferenten Innervation der $\ddot{\mathrm{H} H Z}$ ist noch nicht geklärt. Es wird vermutet, dass diese Verschaltung zum Auflösungsvermögen und der Synchronisation der Gruppe der ÄHZ dient. Die efferente Innervation ist Teil eines Reflexbogens, der auf laute Geräusche ca. ab 75 Dezibel mit einer Abschwächung der Elektromotilität durch die efferenten Kontakte aus dem MOC reagiert. Es wird angenommen, dass dieser Reflex möglicherweise IHZ und Hörnervneurone vor lauten Signalen schützen soll oder dass er zur Diskrimination des Gehörs in lauter Umgebung beiträgt (Reiter und Liberman 1995, Liberman und Guinan 1998, Christopher Kirk und Smith 2003, Maison et al. 2013). 


\section{Mechanotransduktion und innere Haarzellen}

Die mechanischen Eigenschaften der Basilarmembran und selektive Verstärkung durch die ÄHZ ist verantwortlich für eine tonotope Auflösung der Frequenzen bei dem Auftreffen der Schalldruckwellen. Hohe Frequenzen sind am basalen Ende der Basilarmembran repräsentiert und tiefe Frequenzen am apikalen Ende (Liberman 1982, Müller et al. 2005). Die IHZ sind die mechanotransduktiven Sinneszellen des Gehörs. Sie erstrecken sich in einer Reihe auf der Basilarmembran entlang der gesamten Länge des Corti-Organs. IHZ tragen an ihrem apikalen Pol ein „Haarbündel“ aus Stereozilien. Bei Auslenkungen der Basilarmembran werden diese durch Flüssigkeitsbewegungen in der Endolymphe in Bewegung versetzt. Die Scherbewegung der Stereozilien übt Zug auf die „Tip-Links“aus , filäre Strukturen aus Protocadherin 15 und Cadherin 23, mit denen sie untereinander verbunden sind. Dadurch öffnet sich ein Mechanotransduktionskanal, vermutlich ein TMC (transmembrane channel) (Holt et al. 2014) und es kommt zum Kaliumeinstrom aus der Endolymphe (Sewell 1996, Corey 2006).

Die darauf folgende Depolarisation der Zelle führt zu einer kalziumabhängigen Exozytose von glutamatgefüllten synaptischen Vesikeln an den Bändersynapsen der Haarzelle. Diese Bändersynapse ist in ihrer Morphologie und molekularem Aufbau spezifisch für die IHZ und unterscheidet sich von Bändersynapsen anderer sensorischer Systeme. Stimulusgetriggerte Ausschüttung von Glutamat in den synaptischen Spalt erzeugt postsynaptische Potentiale an den Axonendigungen der Typ I-Spiralganglienneuronen, auch postsynaptische Boutons genannt. Schon die kleinsten postsynaptischen Potentiale können dabei Aktionspotentiale in den Axonen erzeugen (Rutherford und Pangršič 2012).

Über diese Fasern, die den Hörnerven bilden, wird neuronale Aktiviät an den Nucleus cochlearis und diverse andere zentrale Verschaltungspunkte weitergeleitet. Jedes Spiralganglienneuron (SGN) kontaktiert dabei nur eine einzige Bändersynapse. Diese besondere Struktur ist vermutlich für die einzigartige Leistung der IHZ im Bezug auf zeitliche Präzision und Bandbreite von Informationsvermittlung verantwortlich. 


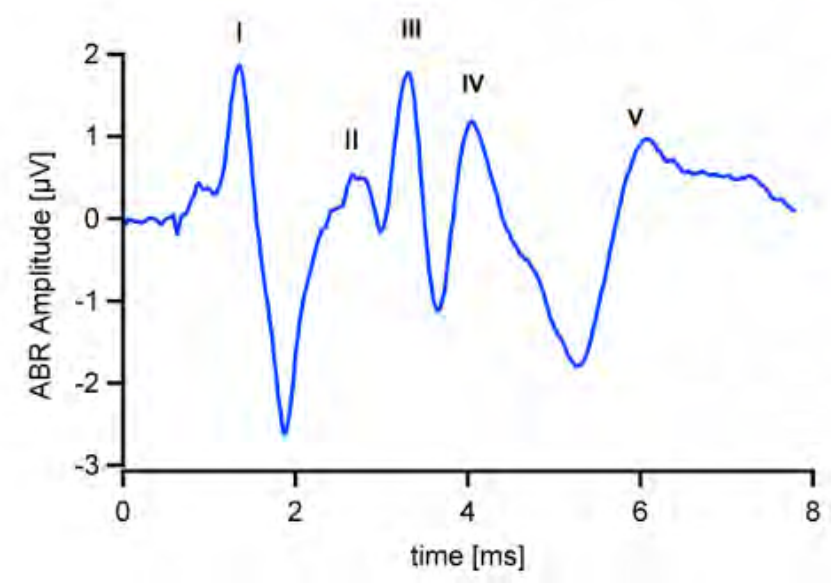

Abbildung 1.1 - Akustisch evozierte Potentiale der Maus nach 80 dB Klick-Stimulus

\subsection{Audiologische Diagnostik}

\section{Akustisch evozierte Potentiale}

Um die Funktion des Corti-Organs und seiner Sinneszellen in vivo beurteilen zu können, gibt es einige objektive Untersuchungsmethoden, die bei Menschen und in Tiermodellen etabliert wurden. Die objektive Hörprüfung durch Testung der otoakustischen Emissionen und die Hirnstammaudiometrie sind seit 2009 in Deutschland ein fester Bestandteil des Neugeborenen-Screenings, um angeborene Hörstörungen so früh wie möglich zu diagnostizieren (Gemeinsamer Bundesausschuss der Ärzte und Krankenkassen, Anlage 6 2008).

Die Aufnahme von akustisch evozierten Potentialen (AEP), auch Hirnstammaudiometrie genannt, ist ein Verfahren zur Hörschwellenbestimmung, das keine aktive Mitarbeit des Versuchsobjektes vorraussetzt. Dabei wird ein akustischer Reiz vielfach wiederholt präsentiert und die neuronale elektrische Aktivität über Elektroden am Kopf abgeleitet. Über meist mehrere tausend Mittelungen der ersten $10 \mathrm{~ms}$ nach Stimulusgabe zeichnet sich die spezifische, evozierte Summenantwort des Hörnerven und der Hörbahn ab, während unspezifische neuronale Hintergrundaktivität herausgemittelt wird.

Die evozierten Potentiale zeigen eine charakteristische Wellenform, die sich in verschiedenen Spezies leicht unterscheidet, aber innerhalb der Individuen einer Art sehr konstant ist (Jewett et al. 1970). Es gibt verschiedene Arten von Stimuli, deren Prozessierung in der Hörbahn 
sich unterscheidet. Präsentiert werden z.B. Klickreize, Tone-Bursts verschiedener Frequenz oder Sprache. Die Bestimmung der AEP-Schwelle erfolgt meist als die geringste Intensität des Stimulus, die eine reproduzierbare, abgrenzbare Wellenform verursacht.

Diese Potentiale mit unterschiedlichen Latenzzeiten können verschiedenen Ursprungsorten zugeordnet werden. Nach Studien von Melcher et al. an der Katze stammt die erste Welle von peripheren Neuronen nahe des Corti-Organs, und die zweite bis vierte Welle von verschiedenen Zellgruppen aus anteroventralen und posteroventralen Nuclei cochlearesNeuronen, sowie ipsilateralen und kontralateralen Olivenkern-Neuronen. Die fünfte Welle stammt von zentralen Nuclei cochleares-Neuronen mit tiefer charakteristischer Frequenz (Melcher et al. 1996). So kann periphere und zentrale Beteiligung der Hörbahn durch Vergleich von Amplitude und Latenzen der neuronalen Potentiale eingeschätzt werden.

\section{Otoakustische Emissionen}

1978 beschrieb D. T. Kemp erstmals otoakustische Emissionen: Töne, die er bei Stimulation der Kochlea mit Tönen anderer Frequenzen im geschlossenen äußeren Gehörgang aufnehmen konnte. Otoakustische Emissionen (OAE) sind Schallereignisse, von denen angenommen wird, dass sie durch die aktiven Prozesse der ÄHZ entstehen.

Die Motilität der ÄHZ erzeugt eine eigene Wanderwelle, die das ovale Fenster erreicht und durch das Mittelohr Impulse an das Trommelfell weiterleitet. Die dort entstehenden Vibrationen können als Schalldruck-Emissionen mit sensiblen Mikrophonen detektiert werden . Man unterscheidet zwischen unterschiedlichen Formen otoakustischer Emissionen. Es gibt spontane Emissionen oder durch elektrische Stimulation der Kochlea ausgelöste elektrisch evozierte otoakustische Emissionen (Kemp 1978).

In der auditorischen Diagnostik werden hauptsächlich TEOAEs (transiente otoakustische Emissionen) oder DPOAEs (Distorsionsprodukt otoakustischer Emissionen) verwendet. Transiente otoakustische Emissionen werden bei einer Stimulation mit kurzem Schallereignis, etwa einem Klick, ausgelöst. Die Präsentation zweier stationärer Sinustöne unterschiedlicher Frequenzen erzeugt Intermodulationen anderer Frequenzen, das sogenannte Distorsionsprodukt otoakustischer Emissionen. Wenn otoakustische Emissionen vorhanden sind, kann man auf intakte Funktion des endokochleären Verstärkers schließen. Außerdem ist unbeeinträchtige Konduktivität des Mittelohrs eine Vorraussetzung. Damit ist die Messung 
otoakustischer Emissionen eine effiziente und nichtinvasive diagnostische Methode, die sowohl in der klinischen Medizin als auch in der Forschung vielfach Verwendung findet (Kemp 2002).

\subsection{Erworbene Schwerhörigkeit}

Bei Menschen sind Beeinträchtigungen des Hörvermögens die häufigste Funktionsstörung eines Sinnesorgans. Laut WHO sind 5,3\% der Weltbevökerung betroffen (WHO 2012). Schwerhörigkeit oder Taubheit können das Leben der davon Betroffenen stark beeinflussen. Vor allem, wenn Taubheit angeboren ist oder sehr früh auftritt und nicht suffizient therapiert wird, kann der Spracherwerb nicht oder nur teilweise möglich sein. Man spricht in diesen Fällen von prälingualer Gehörlosigkeit.

Der Grund für die Taubheit kann an vielen Orten innerhalb der komplexen Verschaltung der Hörbahn liegen. Man unterscheidet zwischen der Schallleitungsschwerhörigkeit, deren Ursache im Außen- oder Mittelohr liegt und Schallempfindungsschwerhörigkeit, bei der Innenohr oder Hörnerv betroffen sind. Letztere wird weiter unterteilt in Verstärkerdefekte, audiologische Synaptopathien und Neuropathien und globale Dysfunktion (Strenzke et al. 2008).

\subsubsection{Lärm- und altersabhängige Schwerhörigkeit}

In einer älter werdenden Gesellschaft, die zudem ständig Beschallungen ausgesetzt ist, wird Hörverlust im Alter ein immer wichtigeres Thema. Schwerhörigkeit ist mittlerweise die zweithäufigste chronische Einschränkung (years lived with disease) im Erwachsenenalter (Mathers et al. 2000). Zudem ist diese Sinnesbeeinträchtigung nicht leicht zu behandeln oder zu verhindern, da zu Ursache und beeinflussenden Faktoren noch zu wenig bekannt ist. In großen Querschnittsstudien wurden verschiedene prädisponierende Faktoren gefunden, die das Hörvermögen im Alter beeinflussen: Die individuelle genetische Ausstattung, Krankheiten wie Mittelohrentzündungen oder M. Menière, ototoxische Medikamente und Lärmexposition (Gates et al. 2000, Bielefeld et al. 2010). Altersschwerhörigkeit wird vielfach mit Lärmschwerhörigkeit in Verbindung gebracht. Die Krankheitsbilder ähneln sich klinisch und morphologisch und scheinen sich wechselseitig zu beeinflussen. Bei Menschen 
wurde beobachtet, dass Lärmexposition eine spätere Altersschwerhörigkeit beschleunigt und exazerbiert, auch wenn die Exposition schon Jahre zurückliegt (Gates et al. 2000). Das konnte auch im Tiermodell nachgestellt werden (Kujawa und Liberman 2006). Das Innenohr scheint weiterhin im Alter immer empfindlicher auf Lärm zu reagieren (Sun et al. 1994, Miller et al. 1998). Von der Begutachtung menschlicher Felsenbeine ausgehend, wurden vier verschiedene morphologische Veränderungen bei der Altersschwerhörigkeit mit ihrem audiologischen Phänotyp assoziiert: I. sensorisch: Verlust von IHZ und ÄHZ. II. neural: Verlust von SGN. III. metabolisch: Veränderungen der Endolymphe durch striale Pathologien. IV. kochleär konduktiv: Veränderungen der Schwingungseigenschaften der Basilarmembran (Schuknecht et al. 1974, Schuknecht und Gacek 1993, Gates und Mills 2005, Perez und Bao 2011).

Lange wurde angenommen, dass vor allem der Haarzellverlust den größten Einfluss auf die Altersschwerhörigkeit hat, da die Hörschwellenverschiebung, vor allem im Hochfrequenzbereich sehr gut mit dem Verlust von ÄHZ und IHZ am basalen Ende der Kochlea korreliert werden konnte. Die ÄHZ sind anfällig gegenüber ototoxischen Medikamenten und Lärm (Wang et al. 2002, Rybak und Ramkumar 2007).Wenn ihre Funktion als kochleärer Verstärker wegfällt, kann der Schwellenschwund 40 bis 50 dB betragen (Dallos 1992). Doch eine Akkumulation von Lärmschädigungen scheint nicht alleine für die Altersschwerhörigkeit verantwortlich zu sein. Auch in Tiermodellen, die in schallarmer Umgebung alterten, fand sich großflächiger Verlust von ÄHZ im Alter (Tarnowski et al. 1991). Eine striale Dysfunktion wurde ebenfalls vielfach als Ursache für Haarzellverlust und Altersschwerhörigkeit diskutiert (Hequembourg und Liberman 2001).So scheinen sich die Pathologien auch untereinander zu beeinflussen. Nach der selektiven Vernichtung von IHZ mittels ototoxischer Medikamente kommt es zu sekundärer Degeneration der Spiralganglienneurone (Ding et al. 1999), aber auch primär, ohne gleichzeitigen Verlust von IHZ wurde ein Verlust von Nervenfasern beobachtet, z.B. nach Lärm (Kujawa und Liberman 2006, 2009) und bei einigen genetischen Ursachen für Schwerhörigkeit (Stankovic et al. 2004, Seal et al. 2008, Glueckert et al. 2003).

\subsection{Angeborene Schwerhörigkeit}

Angeborene Schwerhörigkeit kann im Rahmen von Syndromen auftreten und mit anderen Symptomen vergesellschaftet sein. Diese Fälle machen ca 30\% der angeborenen Schwerhö- 
rigkeit aus. Dabei ist der Ort der Schädigung sehr heterogen: Mittelohrdefekte, Innenohrdefekte oder Mischformen kommen als Ursache in Frage.

Bei nichtsyndromaler, angeborener Schwerhörigkeit liegt die Ursache zumeist bei Innenohr und Hörnerven. Sie wird dann zu den sensorineuralen Schwerhörigkeiten gezählt (Moser et al. 2013, Petit et al. 2001). Durch genetische Screeningverfahren wurde mittlerweile in einigen Fällen die der Schwerhörigkeit zugrunde liegende Genmutation identifiziert und betroffene Proteine konnten in ihrer Rolle in der Hörbahn charakterisiert werden.

Die häufigste Ursache nichtsyndromaler Schwerhörigkeit ist eine Mutation in den Genen, die für die Gap Junction-Proteine Connexin 26 und Connexin 32 codieren (Petit et al. 2001, Nickel und Forge 2008, Kelsell et al. 1997). In diesen Fällen führen Veränderungen der endokochleären Ionenhomöostase zu Dysfunktionen der Rezeptorzellen. Andere Genmutationen beeinflussen die Verstärkerfunktion der ÄHZ (Liberman et al. 2002) oder die elektromechanische Transduktion durch die Haarbündel der IHZ (Gibson et al. 1995). In den letzten Jahren wurden einige Mutationen identifiziert, die die Funktion der Bändersynapse der IHZ beeinträchtigen. Eines dieser Proteine ist Otoferlin. Mutationen des für Otoferlin kodierenden Gens wurden 1999 als Ursache der nichtsyndromalen rezessiven Taubheitsform DFNB9 entdeckt. (Yasunaga et al. 1999, Varga et al. 2003). Mutationen im für Otoferlin kodierenden Gen scheinen in Spanien bis zu 8\% der Fälle von schwerer nichtsyndromaler prälingualer Gehörlosigkeit zu verursachen (Rodríguez-Ballesteros et al. 2008).

\subsubsection{Otoferlin}

Otoferlin is ein Transmembranprotein aus der Familie der Ferline und homolog mit dem C. elegans-Protein FER-1. Es beeinhaltet 6 C2-Domänen (Yasunaga et al. 2000, 1999). Beim Menschen wurden verschiedene, unterschiedlich lange Isoformen identifiziert. Die kurzen Isoformen, die nur drei C2-Domänen tragen, wurden in verschiedenen Geweben nachgewiesen, unter anderem Herz und Pankreas, während die lange Isoform mit 6 C2Domänen nur im Gehirn und vestibulokochleären System gefunden wurde.

Die genaue Funktion von Otoferlin ist noch nicht gänzlich geklärt. Andere Ferline, Dysferlin und Myoferlin sind beteiligt an Membranfusionen. Die C2 Domänen dieser Ferline können Lipidmembranen binden und Membranfusionen beschleunigen (Marty et al. 2013). Es wurde früh vermutet, dass Otoferlin eine ähnliche Rolle in der IHZ übernehmen könnte und so 
auch an der Exozytose in der IHZ beteiligt sei (Yasunaga et al. 2000, Roux et al. 2006). Unterstützt und weiter präzisiert wurde diese Hypothese durch eine Vielzahl folgender Untersuchungen. Es konnte mithilfe von Immunogold-Markierung in Elektronenmikroskopischen Aufnahmen die Lokalisation von Otoferlin an synaptischen Vesikeln nahe der Bandsynapse gezeigt werden (Roux et al. 2006), desweiteren die Interaktion mit synaptischen SNARE-Proteinen und den Kalziumkanälen $\mathrm{Ca}_{V} 1.3$ (Roux et al. 2006, Ramakrishnan et al. 2008). In immunhistochemischen Färbungen mit anti-Otoferlin-Antikörpern wurde die Verteilung von Otoferlin in der gesamten IHZ, seine Kolokalisation mit Membranen und Golgimarkerproteinen gezeigt (Roux et al. 2006, Schug et al. 2006, Heidrych et al. 2008). So wurde auch eine Beteiligung an der Regulation des Trans-Golgi-Netzwerks vermutet.

In einem Mausmodell mit Otof-Knockout-Mäusen (Otof ${ }^{-/}{ }^{-}$) konnte die Funktion des Proteins eingehender charakterisiert werden (Roux et al. 2006, Pangršič et al. 2010). OtofKnockout-Mäuse weisen einen audiologischen Phänotyp auf, der auf eine auditorische Synaptopathie schließen lässt. Akustisch evozierte Potentiale sind nicht auslösbar, doch die Funktion der ÄHZ, durch otoakustische Emissionen evaluiert, scheint unbeeinträchtigt. Elektrische Stimulation des Hörnerven ist möglich (eABR). Vestibuläre Defekte oder andere neurologische Ausfälle fielen nicht auf.

Elektrophysiologische Untersuchungen zeigten in vitro, dass es in Abwesenheit von Otoferlin zum fast vollständigen Verschwinden der kalziumabhängigen Exozytose kam, während Kalziumströme normal waren.

Was an synaptischer Übertragung bleibt ist eine langsame, stimulationsunabhängige Transmitterfreisetzung, die einige seltene exitatorische postsynaptische Potentiale mit geringer Amplitude erzeugt (Pangršič et al. 2010, unveröffentlichte Daten, Dr. Hideki Takago). Doch welche Rolle genau spielt Otoferlin bei der Exozytose? Es scheint nicht notwendig für die Entwicklung oder Reifung der Bandsynapse zu sein, ebensowenig für die Bildung synaptischer Vesikel und ihren Transport zu der Bandsynapse und Zellmembran (Roux et al. 2006, Pangršič et al. 2010). Zunächst wurde eine Funktion von Otoferlin als Kalziumsensor für die kalziumabhängige Exozytose vermutet (Roux et al. 2006). Eine weitere Vermutung entstand aus der Studie eines weiteren Mausmodells mit einer missense Mutation der C2F-Domäne Otoferlins (Pachanga-Mausmodell). Diese Mäuse zeigten reduzierte Otoferlinkonzentrationen in den IHZ und in elektrophysiologischen Versuchen eine normale Ausschüttung des readily releasable pool (RRP), aber reduzierte andauernde Exozytose. Vermutet wurde ein Defekt bei dem Vorgang, neue synaptische Vesikel dem präsynaptischen RRP bereitzu- 
stellen und somit ein Versagen bei länger andauernder Stimulation. Bei Ableitungen aus dem Hörnerven wurde die Synchronität der postsynaptischen Aktivität zum Stimulus besser, je langsamer die Wiederholungsrate war (Pangršič et al. 2010). Otoferlin scheint auch an der Wiederauffüllung des RRP und dem priming der synaptischen Vesikel beteiligt zu sein (Pangršič et al. 2010, 2012, Duncker et al. 2013).

\subsubsection{DFNB9 - eine Synaptopathie}

DFNB9 (Deafness, Neurosensory, Autosomal Recessive) ist eine nichtsyndromale Gehörlosigkeit, die auf Mutationen im OTOF-Gen beruht. Betroffene Patienten wurden in mehreren Studien genetisch und audiologisch untersucht. Es sind 42 pathogene Mutationen des $O T O F$-Gens bekannt, die meisten davon inaktivierende Mutationen, die zu reduzierter oder fehlender Expression des Proteins führen (Rodríguez-Ballesteros et al. 2003, 2008, Rouillon et al. 2006).

In den meisten Fällen von DFNB9 Betroffenen bestand prälinguale Taubheit. Die akustisch evozierten Potentiale waren nicht ableitbar oder verzögert und zeigten reduzierte Amplituden (Santarelli et al. 2009). Die Mittelohrreflexe fehlten bei allen getesteten OTOF-MutationsBetroffenen (Rouillon et al. 2006, Santarelli et al. 2009).Otoakustische Emissionen waren in vielen Fällen vorhanden und wiesen somit auf eine ungestörte Elektromotilität der ÄHZ hin, passend zu der Definition als auditorische Synaptopathie (Brandt et al. 2003, Moser et al. 2013). Allerdings war dieses Bild nicht sehr homogen. In einigen Studien hatten nur die Hälfte der Studienteilnehmer mit DFNB9 messbare OAE auf einem oder beiden Ohren. In den anderen Fällen fehlten sie schon bei der ersten Untersuchung oder waren bei späteren Follow-up-Untersuchungen nicht mehr messbar, obwohl sie initial vorhanden gewesen waren (Rodríguez-Ballesteros et al. 2003, Varga et al. 2003).

Im Durchschnitt waren die Patienten ohne OAEs um einiges älter als diejenigen mit erhaltenen OAE. Rouillon et al. beobachtete 2006 zwei Kinder mit DNFB9, deren otoakustische Emissionen initial vorhanden waren, jedoch dann im Laufe der ersten zwei Lebensjahre verschwanden. Es wurde vermutet, dass die Versorgung der Kinder mit leistungsstarken Hörgeräten zu einer Schädigung der ÄHZ geführt haben könnte. Eine andere Vermutung war, dass die Otoferlin Mutation die Funktion oder den Erhalt der ÄHZ beeinflussen könnte (Varga et al. 2003, Rouillon et al. 2006). 


\subsection{Ziele der Arbeit}

Mutationen, die zur Reduktion oder Abwesenheit des Proteins Otoferlin führen, wurden in zahlreichen Studien in Menschen mit DFNB9 oder eigens generierten Mausmodellen untersucht. Dabei wurden unter anderem Locus und Art der Mutation, Ausmaß des Hörverlusts und Funktion der ÄHZ, als auch synaptische Transmission an der IHZ in Mutanten und Ultrastruktur der Bändersynapsen beobachtet, um die Funktion Otoferlins genauer charakterisieren zu können (Yasunaga et al. 1999, Rodríguez-Ballesteros et al. 2003, Roux et al. 2006, Pangršič et al. 2010, 2012). Es wurden einige Hinweise auf eine frühe und schnell progrediente Degeneration des Corti-Organs und des Hörnervens in Abwesenheit von Otoferlin gefunden, wie z.B. die Reduktion der Anzahl von Bändersynapsen um die Hälfte im Alter von 2 Wochen (Roux et al. 2006).

Desweiteren ergab sich die Vermutung, dass auch externe Faktoren, wie Lärmexposition, auf Otof-Knockout-Mäuse einen stärkeren Einfluss haben könnten als auf normal hörende Mäuse, da protektive Reflexe, wie in Kapitel 1.1 auf Seite 2 beschrieben, fehlen. Dadurch könnte der häufige Verlust von otoakustischen Emissionen bei Patienten mit DFNB9 erklärt werden.

In dieser Arbeit sollten die von Degeneration betroffenen Strukuren im Innenohr der OtofKnockout-Mäuse ausgemacht werden und Ausmaß sowie zeitlicher Verlauf der Degeneration qualitativ und quantitativ untersucht werden. Die Hypothese einer größeren Lärmempfindlichkeit der Otof-Knockout-Mäuse sollte mithilfe von Lärmexpositionsversuchen getestet werden. 


\section{Material und Methoden}

\subsection{Versuchstiere}

Die in dieser Arbeit verwendeten transgenen Mäuse wurde von Dr. Ellen Reisinger generiert. In den Otof-Knockout-Mäusen (Otof ${ }^{-/-}$) wurde Exon 14 und 15 des Otof-Gens exzidiert, was zu einem Translationsabbruch führte (Reisinger et al. 2011). Der Erfolg wurde per immunhistochemischen Färbungen der Kochlea überprüft, in denen kein Expression von Otoferlin in den Otof-Knockout-Tieren zu entdecken war (Pangršič et al. 2010). Die Mäuse wurden gezüchtet und gehalten in der Tierhaltung des Max-Planck-Instituts für Experimentelle Medizin in Göttingen. Die Tierversuche wurden durch die Tierschutzkommission der Universitätsmedizin Göttingen und des Niedersächsischen Landesamtes für Verbraucherschutz und Lebensmittelsicherheit (LAVES) im Tierversuchsantrag Nr. 33.9-42502-0410/0095 genehmigt. Die hier verwendeten Tiere wurden nach dem Absetzen genotypisiert, die Taubheit der Mutanten wurde außerdem per Hirnstammaudiometrie bestätigt.

In dieser Studie wurden 41 Otof-Knockout-Mäuse, 19 Weibchen und 22 Männchen, und 32 gesunde Wurfgeschwister (Otof ${ }^{+/+}$), 10 Weibchen und 22 Männchen in den Altersgruppen 6 Tage, 6-8 Wochen, 12 Wochen, 24 Wochen und 48 Wochen untersucht. Für die Etablierung der Immunhistochemie-Protokolle und des Lärmtrauma-Protokolls wurden 29 heterozygote Tiere $\left(\right.$ Otof $^{+/-}$) verwendet. In der Kontrollgruppe der Lärmexposition mit $120 \mathrm{~dB}$ über $2 \mathrm{~h}$ wurden vier Wildtyp Mäuse und zwei Heterozygote verwendet. Wir konnten in Voruntersuchungen keinen Unterschied bei Hörschwellen und DPOAE Amplituden zwischen Wildtyp und heterozygoten Tieren feststellen, wie auch in früheren Studien bestätigt (Roux et al. 2006). 


\subsection{Hörtests}

Um, wie oben beschrieben, eine objektive Evaluation des Hörvermögens der Versuchstiere zu erreichen, wurden die Messungen stets im gleichen Raum und mit den gleichen Systemen durchgeführt. Zur Testung des Hörvermögens und zur Hörschwellenbestimmung wurden die Mäuse intraperitoneal anästhesiert, mit einer Mischung aus Ketamin (125 mg/kg Körpergewicht) und Xylazin (2,5 mg/kg Körpergewicht). Die Körpertemperatur der anästhesierten Tiere wurden mittels einer rektalen Temperatursonde überwacht und mit Wärmeplatten (Homeothermic blanket control apparatus, Harvard apparatus) bei $37,5^{\circ} \mathrm{C}$ gehalten

Die Tiefe der Narkose wurde mithilfe der Darstellung der Herzfrequenz per Oszillographen (HM208, HAMEG GmbH, Frankfurt Germany) und durch regelmäßige Kontrollen überwacht.

\subsubsection{Hirnstammaudiometrie}

In einem reflexionsarmen Raum mit schallabsorbierender Auskleidung wurde das jeweilige Versuchstier auf der Wärmematte neben den Lautsprecher (Ultra-high Frequency Transducer JBL 2402H, JBL Professional Northridge, California 91329 USA) platziert. Zwischen Lautsprecher und Pinna des Tieres war 7,5 cm Abstand.

Zur Ableitung der evozierten Potentiale wurden drei subkutane Nadelelektroden angebracht. Die Referenzelektrode wurde unter der Pinna, am Mastoid anliegend platziert, die Indifferenzelektrode am Vertex und die Erdelektrode an der rechten Flanke.

Über Kabel wurden die Elektroden mit einem empfindlichen Bioverstärker (JHM NeuroAmp 401, J.Helbig Messtechnik, Mainaschaff, Germany) verbunden, durch den eine Verstärkung des Signals um den Faktor 10.000 und eine Bandpassfilterung zwischen 0,4 und $4 \mathrm{kHz}$ erfolgte. Der Stimulus wurde nach Festlegung der Parameter von der SigGen Software (Biosig32, Open Source Software Library, Sourceforge) generiert und mittels eines EchtzeitProzessors und zwei Abschwächern (beides TDT System II, Tucker-Davies-Technologies, Ft Lauderdale, FL, USA) ausgegeben und in seiner Intensität kontrolliert.

Es wurde mit Klickreizen stimuliert in einer Repetitionsrate von $20 \mathrm{~Hz}$ und Intensitäten von 20-100 dB. Zusätzlich wurden Tonimpulse (12 ms inkl. 2x1 ms $\cos ^{2}$-Rampe) unterschiedlicher Frequenzen von 6-32 kHz und Intensitäten von 10-100 dB verwendet. 
Mithilfe des Biosig-Programms wurden die Messungen weiter gefiltert, gemittelt über 2x ca. 1000 Wiederholungen und anschließend gespeichert. Die Hörschwelle wurde nach subjektiver, visueller Beurteilung der Wellenform bestimmt. Die geringste Intensität, bei der Potentiale s. Abb 1.1 deutlich von der Hintergrundaktivität abgrenzbar waren, wurde als Hörschwelle definiert.

\subsubsection{Distorsionsprodukte otoakustischer Emissionen}

Die Messung der Distorsionsprodukte otoakustischer Emissionen (DPOAE) erfolgte im geschlossenen Feld. In einer 1,5 m x 1,5 m x 1,5 m Holzbox mit schallabsorbierender Auskleidung wurde das anästhesierte Versuchstier auf einer Wärmeplatte mit rückgekoppelter Temperatursonde platziert. Eine selbstangefertigte Plastiksonde wurde im äußeren Gehörgang der Maus möglichst nah an das Trommelfell platziert. Die Sonde beeinhaltete ein sensitives Mikrophon MKE-2 (Sennheiser, Hannover, Germany) und zwei Silikonschläuche, die in Verbindung mit zwei MF1-S Lautsprechern standen (Tucker Davis Technologies, Ft Lauderdale, FL, USA). So wurden die zwei Primärtöne f1 und f2 präsentiert und über das Mikrophon erfolgte rückgekoppelt die Anpassung der Insensität. Mithilfe einer Matlab-Routine (Mathworks, The MathWorks, Inc., Natick, MA USA; geschrieben von G. Hoch) wurden die Parameter der Messung bestimmt. Stimuli wurden im Frequenzverhältnis f2 $=1.2 \mathrm{x}$ f1 präsentiert in jeweils 16 Sekunden Tönen mit f1 Frequenzen von 6-23 kHz und Intensitäten von 10 bis $60 \mathrm{~dB}$, kontrolliert durch die Abschwächer (TDT). Aufgenommen wurden die Stimuli über Mikrophon und Soundkarte (Terratec DMX 6 Fire USB soundcard, ultron AG, Alsdorf, Deutschland). Die aufgenommenen Emissionen wurden digitalisiert und verstärkt. Nach Bearbeitung mittels Fast-Fourier-Transformation wurden die Amplituden der DPOAE bei 2x f1-f2, die Amplituden der Primärtöne und das Restrauschen bestimmt, angezeigt und anschließend gespeichert. Otoakustische Emissionen wurden bei allen Versuchstieren an beiden Ohren gemessen und anschließend beide Seiten gemittelt.

\subsection{Lärmtrauma}

Das Lärmtrauma wurde in einer $91 \mathrm{~cm}$ x 96cm x 91 cm Holzbox durchgeführt. Durch gut reflektierende Wände, die in schrägen Winkeln zueinander stehen, wurde ein diffuses Schallfeld mit gleichmäßiger Beschallung erzeugt. 
Die Versuchstiere, immer paarweise ein Otof $^{-/-}$-Tier und ein gesundes Wurfgeschwistertier, wurden in wachem Zustand in einem Käfig aus Gitterdraht auf einer rotierenden Platte platziert. Der Lautsprecher (Beyma TD-164) war ca. $53 \mathrm{~cm}$ vom Kopfniveau der Versuchstiere entfernt. Eine Matlab-Routine (Dr. A. Brandt) steuerte über die Soundkarte (DMX 6fire USB, Terratec) einen Verstärker (A500, 600 Watt Behringer, Music Group IP Ltd, Philippines) der ein auf $4 \mathrm{kHz}$ bis $16 \mathrm{kHz}$ gefiltertes weißes Rauschen produzierte. Lautstärkepegel wurde kontrolliert mithilfe eines in die Box eingebauten Mikrophons (ECM8000, Behringer) und eines weiteren Kalibriermikrophons (Typ2670, Kapsel 4939, Brüel \& Kjær Sound \& Vibration Measurement A/S, Naerum, Denmark), das im Käfig auf Höhe der Versuchstiere angebracht war und mitrotierte.

Expositionszeiten waren 15 min mit $103 \mathrm{~dB}$ für die schwache Lärmexposition und $2 \mathrm{~h}$ mit $120 \mathrm{~dB}$ für das starke Lärmexpositionsprotokoll.

\subsection{Histologische Untersuchung}

\subsubsection{Präparation des Corti-Organs}

Zur Entnahme des Corti-Organs wurden die Versuchstiere mit $\mathrm{CO}_{2}$ tief betäubt, dekapitiert und die Kopfhaut abpräpariert. Der Schädel wurde sagital in zwei Hälften zerteilt und in eine Petrischale mit phosphatgepufferter Salzlösung (PBS) transferiert. Darin wurde unter dem Mikroskop das Gehirn aus der Kalotte entfernt, um den Porus akustikus internus beidseits freizulegen, dann die Felsenbeinpyramiden aus dem knöchernden Schädel herausgetrennt. Nach Entfernung von Bulla, Ossikelkette und Stapediusmuskel wurde mit einer feinen Pinzette die Kochlea im apikalen Bereich und am runden Fenster eröffnet.

Die Präparate wurden in 4\%ige, eisgekühlte Formaldehydlösung platziert und mit einer feinen Spritze Formaldehyd durch das runde Fenster transfundiert. Darin wurde das Präparat zum Fixieren belassen, die Einwirkzeit variierte dabei je nach weiterer geplanter Vorgehensweise. Für Häutchenpräparate des Corti-Organs wurde die Kochlea für 10 Minuten im Fixativ belassen, für Kryoschnitte wurde 25-30 Minuten lang fixiert.

Die für Häutchenpräparate vorgesehene Kochlea wurde nach der Fixierung für 15 min in eine Dekalzifizierlösung nach Morse (Morse 1945) gebracht, um das knöchernde Schneckenhaus des Corti-Organs aufzuweichen. In PBS Lösung wurde anschließend vorsichtig mit feinen 

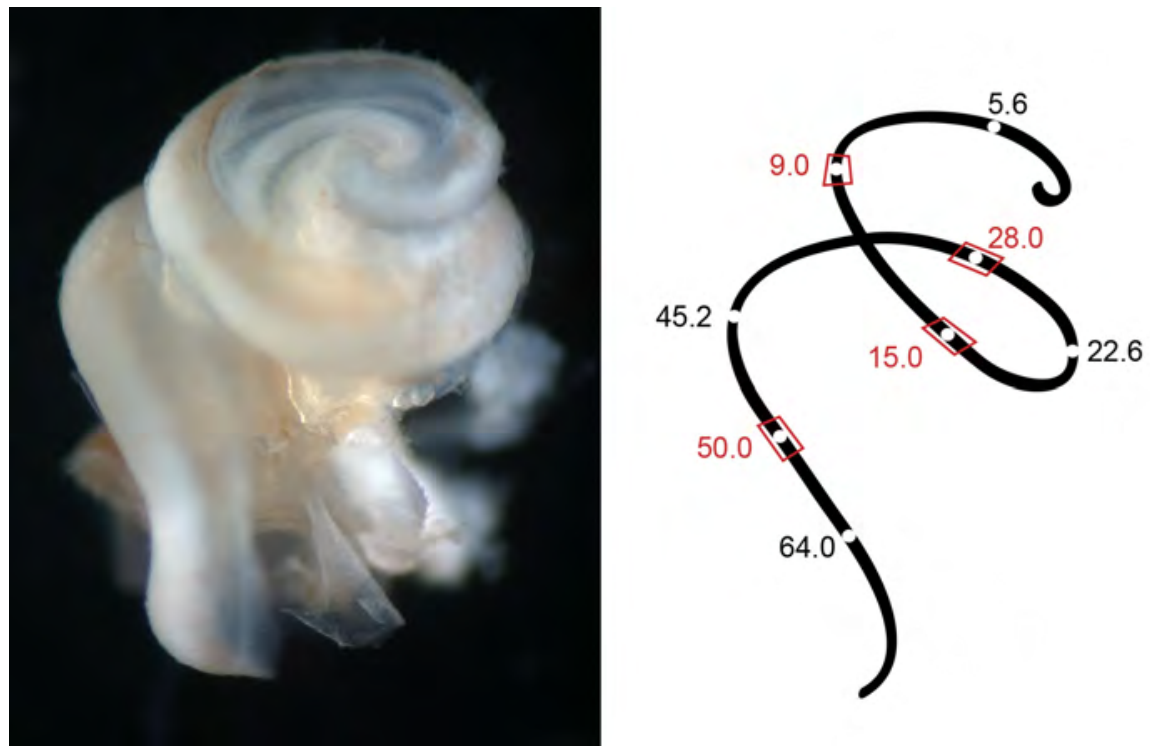

Abbildung 2.1 - Corti-Organ der Maus und Schema der tonotopen Repräsentation der Frequenzen (in $\mathrm{kHz}$ ) auf der Basilarmembran nach Müller et al. 2005, Detailaufnahmen der Inneren Haarzellen wurden bei ca. 9 kHz, 15 kHz, 28 kHz und $50 \mathrm{kHz}$ gemacht

Pinzetten die weiche Knochenhülle vom Corti-Organ getrennt. Die Mäusekochlea besitzt im Gegensatz zur menschlichen nur $1 \frac{3}{4}$ Windungen. Diese wurden freigelegt, bis das basale Ende zu sehen war, und abgetrennt. Das Präparat wurde dann mit einer feinen Schere in drei Abschnitte geteilt. Mit Pinzette und Mikroskalpell wurde schließlich vorsichtig die Stria vaskularis und die Tektorialmembran abpräpariert.

Wenn Kryoschnitte für die Präparate vorgesehen waren, wurden sie für mindestens 2 bis maximal 24 Stunden in der Dekalzifizierungslösung belassen, bis der Knochen ausreichend nachgiebig war. Je nach Alter des Tieres variierte die Härte des Knochens und damit die benötigte Einwirkzeit. Bis zur Einbettung wurde die ganze Kochlea danach in 20\%iger Sulroselösung belassen und dann am Kryotom (2800 Frigocut, Reichert-Jung, Österreich) in $20 \mu \mathrm{m}$ Scheiben geschnitten

\subsubsection{Immunhistochemie}

Zur Färbung wurden die Komplettpräparate zunächst eine Stunde bei Raumtemperatur in einem feuchtgehaltenen Behälter in Goat Serum Dilution Buffer (GSDB) inkubiert. Anschließend wurden sie mit den Primärantikörpern, verdünnt in GSDB, über Nacht bei $4^{\circ} \mathrm{C}$ 
weiter inkubiert. Am folgenden Tag wurden die Primärantikörper in drei Waschschritten à 10 Minuten mit Waschpuffer ausgewaschen und die Sekundärantikörper, wiederum verdünnt in GSDB, zugefügt. Dieser Inkubationsschritt dauerte 1-3 Stunden und wurde bei Raumtemperatur und in einem abgedunkelten Behälter durchgeführt. Im letzten Schritt wurden auch die Sekundärantikörper mit Waschpuffer ausgewaschen und die Präparate auf Objektträger mit einem Tropfen Mowiol Mounting Medium aufgetragen. Darauf wurde möglichst luftblasenfrei ein Deckglas platziert und die Objektträger bis zur Bildaufnahme lichtgeschützt bei $4^{\circ} \mathrm{C}$ aufbewahrt.

Inhaltsstoffe der Lösungen s. Anhang auf S. 50.

Zur Etablierung der Färbeprotokolle wurden zahlreiche Versuche im Voraus durchgeführt. Um möglichst viele Strukturen des Corti-Organs verlässlich anzufärben, entwickelten wir eine Vierfach-Kombination von Antikörperfärbungen. Die Färbung der IHZ ist mithilfe der Kalziumpuffer Calretinin, Calbindin und Parvalbumin möglich. Hier bevorzugten wir Parvalbumin, da dieses auch die SGN und ÄHZ schwach anfärbt sowie die postsynaptischen Boutons der IHZ. Eine spezifische Färbung der postsynaptischen AMPA-Glutamatrezeptoren war hier nicht erfolgreich, vermutlich aufgrund der Dekalzifizierungschritte. Daher färbten wir die SGN-Axone und Boutons mit Na/K-ATPase-Antikörpern. Neurofilament-Antikörper färben ebenfalls die SGN-Axone, allerdings nicht bis zum Kontakt der Boutons mit den IHZ. Die Färbung von C-terminal-binding protein 2 (CtBP2) zeigt recht verlässlich die präsynaptische Struktur der synaptischen Bänder sowie die Nuclei der IHZ und einiger Stützzellen. Um die Quantifizierung der Nuclei zu vereinfachen, benutzten wir zusätzlich Hoechst zur sehr verlässlichen Färbung aller Zellkerne. In einigen Präparaten mit sehr fortgeschrittener Degeneration war die Quantifizierung des Haarzellverlustes nur mithilfe einer spezifischen Färbung der ÄHZ durch Oncomodulin und der IHZ durch Parvalbumin möglich (s. Abb. 3.4 auf S. 25). In den Kryoschnitten verwendeten wir Neurofilament, um die Axone und Zellkörper der SGN darzustellen und Parvalbumin ebenfalls um die SGNZellkörper darzustellen, obwohl dies in den Kryoschnitten nicht in allen Fällen erfolgreich war (s. Abb. 3.7 auf S. 30). 


\section{Primärantikörper}

\begin{tabular}{lll}
\hline mouse CtBP2 & $1: 200$ & BD Bioscience \\
rabbit Na/K ATPase & $1: 100-1: 200$ & Santa Cruz Biotech \\
guinea pig parvalbumin & $1: 200$ & Synaptic Systems \\
goat calretinin CG1 & $1: 300$ & Swant \\
mouse neurofilament & $1: 400$ & Sigma \\
rabbit oncomodulin & $1: 300-1: 1000$ & Swant \\
\hline
\end{tabular}

\section{Sekundärantikörper}

\begin{tabular}{lll}
\hline goat anti guinea pig 488 & $1: 200$ & Invitrogen \\
goat anti rabbit IgG 633 & $1: 200$ & MoBiTec \\
goat anti mouse IgG H+L 568 & $1: 200$ & MoBiTec \\
donkey anti rabbit 647 & $1: 200$ & Invitrogen \\
donkey anti goat 568 & $1: 200$ & Invitrogen \\
donkey anti mouse 488 & $1: 200$ & Invitrogen \\
Hoechst 34580 & $1: 5000$ & Invitrogen \\
\hline
\end{tabular}

\subsection{Konfokalmikroskopie}

Gefärbte Präparate wurden am Konfokalmikroskop untersucht. Verwendete Mikroskope waren ein Leica TCS SP5 (Leica Microsystems, Wetzlar) mit den Lasern DiodenUV 405 nm, Ar 488 nm, DPSS 567 nm, HeNa 633 nm und den Objektiven 10x trocken, 40x Ölimmersion und 63x Ölimmersion. Desweiteren wurde auch ein Leica TCS SP2 mit Ar 488 nm, DPSS $567 \mathrm{~nm}, \mathrm{HeNa} 633 \mathrm{~nm}$ und Objektiven 10x trocken und 63x Glycerinimmersion verwendet.

Aufnahmen wurden mit einer Aufnahmegeschwindigkeit von $400 \mathrm{~Hz}$ in einer Auflösung von 512x512 Pixeln und Lochblende 1 airy mit 2-6 Entrauschungsaufnahmen (frame averages) gemacht. Von jedem Corti-Organ wurden Übersichtsaufnahmen der drei Einzelstücke gemacht, in Einzelschichtaufnahmen mit 10x Objektiv. Danach wurden mindestens vier Detailaufnahmen angefertigt, die entlang der Basilarmembran von apikal nach basal in regelmäßigen Abständen von ca 1-1,5 mm von Apex aus plaziert waren. Die Aufnahmeorte lagen 
ungefähr in Oktavenschritten bei $9 \mathrm{kHz}, 15 \mathrm{kHz}, 28 \mathrm{kHz}$ und $50 \mathrm{kHz}$ nach der tonotopischen Repräsentation der Frequenzen in der Mäusekochlea (Müller et al. 2005).

Diese Detailaufnahmen bestanden aus Z-Stapeln von 5-15 $\mu \mathrm{m}$ Tiefe in z-Achse und 0,2 $\mu \mathrm{m}$ Schrittabstand mit 63x-Objektiv in 3,3fachen digitalem Zoom aufgenommen. Weitere ZStapel-Aufnahmen wurden an derselben Lokalisation mit 40x-Objektiv aufgenommen. Die Schichtendicke wurde jeweils so gewählt, dass Reihen von IHZ und ÄHZ, wenn vorhanden, sichtbar waren. Gefärbte Präparate der Kryoschnitte wurden mit 40x-Objektiv und 1,6fachen digitalem Zoom in Einzelschichtaufnahmen aufgenommen.

\subsubsection{Bilderfassung und -analyse}

Stacks wurden mithilfe der Leica software LAS AF lite (Leica Microsystems, Wetzlar) oder Image J (freeware, National Institute of Health, USA) geladen und analysisiert. Die Länge der Basilarmembran jedes Corti-Organs vom Apex bis zum runden Fenster wurde in den Übersichtsaufnahmen der Einzelstücke ausgemessen, wobei per Hand entlang der Reihe von IHZ eine Linie gezogen wurde. In den Detailaufnahmen wurden die Bändersynapsen pro IHZ gezählt. Als Bändersynapse gezählt wurden deutlich abgrenzbare, punktförmige CtBP2 gefärbte Signale (Schmitz et al. 2000), die mit der IHZ-Plasmamembran (Calretinin und Parvalbuminfärbung) und den postsynaptischen afferenten Nervenfasern (Na/K-ATPaseFärbung) (McLean et al. 2009) assoziiert waren. Das Vorhandensein von inneren und äußeren Haarzellen wurde in Stacks von Nuclei und IHZ-Zellkörper-Färbungen (Hoechst und Parvalbumin) quantifiziert. Gezählt wurde die Anzahl von Nuclei innerer und äußerer Haarzellen, pro Abschnitt Basilarmembran unter den IHZ mit definierter Länge.

In den Kryoschnitten wurde das Areal des Rosenthalkanals mit Image J-Software per Hand umfahren und ausgemessen. In dieser Fläche liegende Nuclei von Neuronen wurden durch ihre Färbung mit Parvalbumin und Neurofilament und durch ihren Hoechst-gefärbten charakteristischen runden Zellkern mit hellen, gut sichtbaren Nucleoli identifiziert (Spatz und Löhle 1995). Alle Neuronen, deren Kern in der Schichtaufnahme angeschnitten war, wurden manuell gezählt. 


\subsection{Statistik}

Die Anwendung statistischer Tests auf die Datensätze wurde mit Hilfe des Instituts für Medizinische Statistik, Göttingen geplant. Statistische Tests wurden mit Statistica (StatSoft Europe GmbH, Phillipines) durgeführt. Es wurden multifaktorielle ANOVA und MannWhitney U-Tests angewandt. In den meisten Gruppen war die Anzahl der Tiere oder Präparate allerdings zu klein, um aussagekräftige statistische Test durchzuführen. In diesen Fällen wurde darauf verzichtet. 


\section{Ergebnisse}

\subsection{Degeneration des Corti-Organs bei Otof-Knockout-Mäusen}

Um die Degeneration des Corti-Organs bei Otoferlin-Mutanten zu untersuchen, wurden Otof-Knockout-Mäuse im Altersverlauf untersucht. Als Kontrolle dienten WildtypWurfgeschwister im gleichen Alter. Untersucht wurden Tiere im Alter von 1 Woche, 8 Wochen, 12 Wochen, 24 Wochen und 48 Wochen. Bei jedem Tier wurde die Hörschwelle und die Amplituden der akustisch evozierten Potentiale bestimmt. Die Aktivität der ÄHZ wurde mithilfe von DPOAE untersucht. Im Anschluss wurden beide Innenohren der Versuchstiere histologisch aufbereitet.

\subsubsection{Von hochfrequent nach niedrigfrequent sich ausbreitender Funktionsverlust der äußeren Haarzellen}

Der genetische Hintergrund der Otof-Mutante ist die C57BL/6-Mauslinie. Für diese Mauslinie ist bekannt, dass sie von früher Altersschwerhörigkeit betroffen ist (Mikaelian et al. 1974, Johnson et al. 1997). Somit erwarteten wir, bei den gesunden Kontrollen in der Hirnstammaudiometrie eine im Alter zunehmende Hochtonschwerhörigkeit zu beobachten. Diese Altersschwerhörigkeit der Otof-Wildtyp-Mäuse betrifft zunächst die höchsten Testfrequenzen und breitet sich im Verlauf auf tiefere Frequenzen aus (s. Abb. 3.1 B)). Die Welle I-Amplitude der Klickstimulus-Potentiale zeigt ab 24 Wochen eine deutliche Reduktion der Amplitude um mehr als $60 \%$ bei $80 \mathrm{~dB}$ Stimulus im Vergleich zu 8 Wochen alten Tieren. Im Alter von 48 Wochen ist die Amplitude bei $80 \mathrm{~dB}$ um mehr als $80 \%$ reduziert (s. Abb. 3.1). 

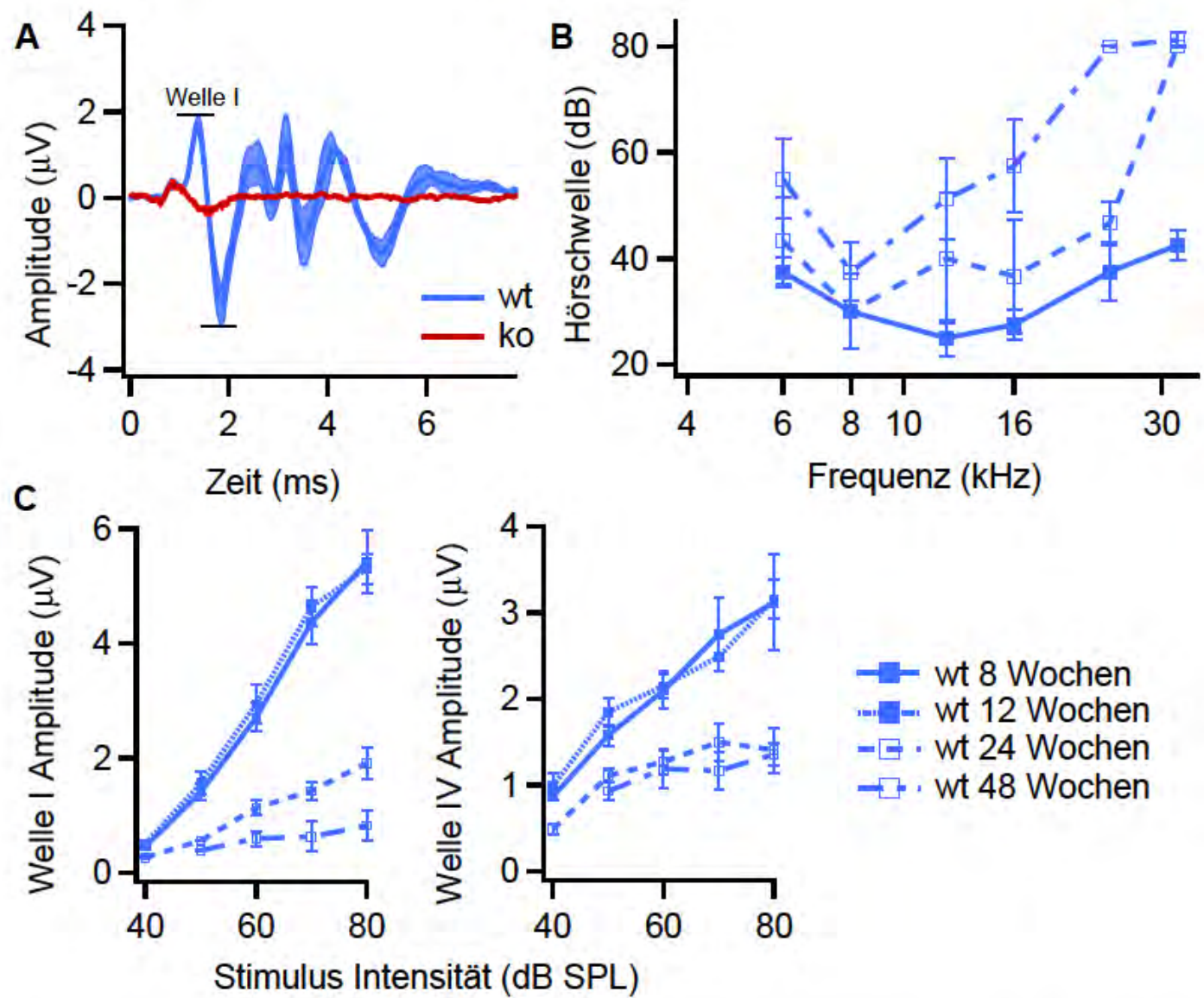

-n- wt 12 Wochen

- - - wt 24 Wochen

-t. wt 48 Wochen

Stimulus Intensität (dB SPL)

Abbildung 3.1 - A)Potentiale von $\mathrm{Otof}^{-/-}$und $\mathrm{Otof}^{+/+}$bei $80 \mathrm{~dB}$ Klick-Stimulus B) Hörschwellen der Otof $^{+/+}$-Mäuse verschiedener Altersgruppen 8 Wochen: $n=4 ; 24$ Wochen: $n=3$, 48 Wochen: $n=4$ C) Welle I- und Welle IV-Amplitude der evozierten Potentiale bei Klickstimulus steigender Intensität 8 Wochen: $n=7,12$ Wochen: $n=3,24$ Wochen: $n=3$, 48 Wochen: $n=3$ 

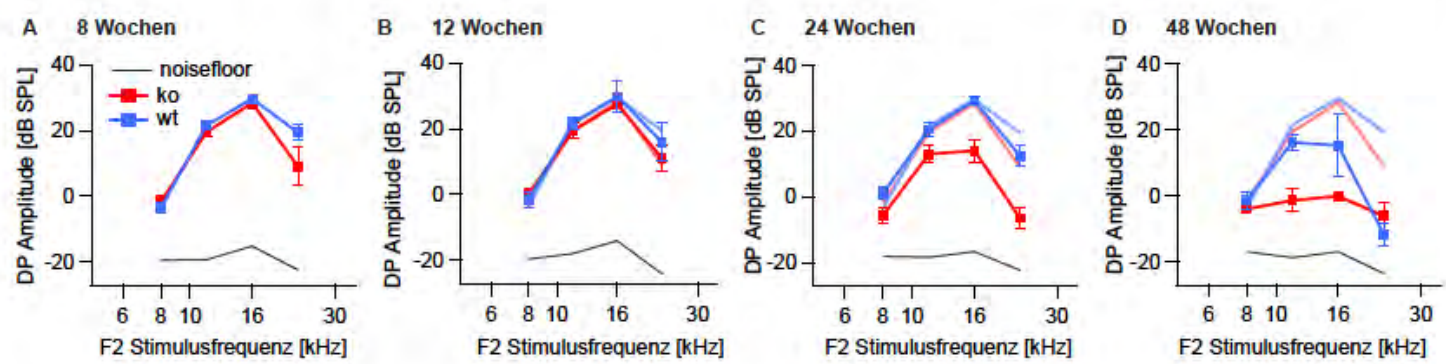

Abbildung 3.2 - DPOAE-Amplituden von Otof-Wildtyp und Otof-Knockout bei F2:60dB A) 8 Wochen $k o: n=6, w t: n=6$ B) 12 Wochen $k o: n=5$, wt: $n=3$ C) 24 Wochen $k o: n=5$, wt: $n=6$ D) 48 Wochen $k o: n=4, w t: n=4$

A

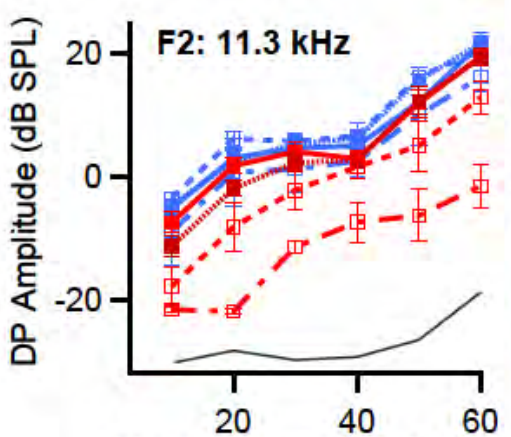

Stimulus Intensität (dB SPL)
B

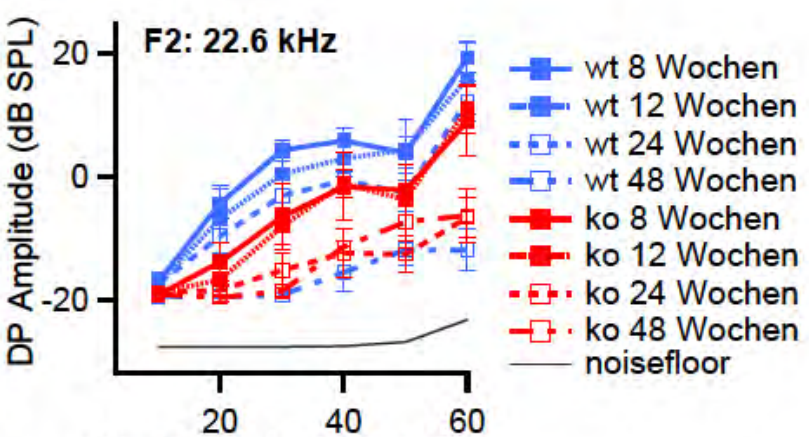

Stimulus Intensität (dB SPL)

Abbildung 3.3 - Wachstumsfunktionen der DPOAE-Amplituden bei Teststimulusfrequenz von A) 11.3 $\mathrm{kHz}$ und B) $22.6 \mathrm{kHz}$; Tierzahlen entsprechen denen der Abb.3.2

In Otof-Knockout-Mäusen können außer einem Rezeptorpotential keine Reizantworten evoziert werden s. Abb 3.1 A).

Im Gegensatz zu den AEPs, können die DPOAEs in Otof-Knockout und Otof-Wildtyp verglichen werden. Hier zeigte sich im zeitlichen Verlauf eine deutlich frühere und schneller progrediente Reduktion der otoakustischen Emissionen in Otof-Knockout-Mäusen (s. Abb.3.2).

Im Alter von 8 Wochen zeigen Otof-Knockout-Mäuse bei der höchsten Testfrequenz von F2: $22.6 \mathrm{kHz}$ schon eine geringe Amplitudenreduktion, die sich aber bei 12 Wochen alten Tieren noch nicht wesentlich verschlechtert hat. Bei 24 Wochen alten Otof-Knockout-Tieren sind alle Testfrequenzen betroffen, dabei f2: $22.6 \mathrm{kHz}$ am stärksten, bei F2: $8 \mathrm{kHz}$ und $12 \mathrm{kHz}$ 
moderat. Im Alter von 48 Wochen sind alle Testfrequenzen betroffen und die Amplituden gleichförmig auf geringes Niveau reduziert.

Otof-Wildtyp-Tiere zeigen einen DPOAE-Amplitudenverlust mit ähnlichem Muster, der zuerst die höchsten Testfrequenzen betrifft und mit zunehmendem Alter auch die mittleren und tiefen Testfrequenzen. Allerdings beginnt dieser Verlust später als bei den Otof-KnockoutMäusen und scheint langsamer fortzuschreiten. Auch im Alter von 24 Wochen zeigen Otof-Wildtyp-Mäuse bei den hohen Testfrequenzen nur einen dezenten Amplitudenverlust. Im Alter von 48 Wochen dagegen ist auch beim Wildtypen eine deutliche Funktionseinbuße der ÄHZ bei F2:22.6 kHz und F2:16 kHz zu erkennen.

Die Wachstumsfunktionen der DPOAE s. Abb.3.3 zeigen einen Amplitudenverlusts der gleichmäßig voranschreitet und zuerst die hohen Testfrequenzen betrifft und später die tieferen Testfrequenzen. In seiner Form ist dieser in Otof-Knockout- und Otof-WildtypTieren sehr ähnlich, beginnt jedoch im Otof-Knockout wesentlich früher und schreitet schneller voran. Bei F2: $11.3 \mathrm{kHz}$ sind die Amplituden des Otof-Wildtyps bis 48 Wochen unverändert, die des Otof-Knockout nehmen dagegen mit dem Alter stetig ab. Bei F2: $22.6 \mathrm{kHz}$ ist auch in Otof-Wildtyp-Mäusen ein Amplitudenverlust zu sehen, der der OtofKnockout-Mäuse ist wiederum wesentlich weiter fortgeschritten und schon mit 8 Wochen zu sehen.

\subsubsection{Langsame Degeneration von äußeren und inneren Haarzellen}

An Häutchenpräparaten des Corti-Organs wurden mittels immunhistochemischer Färbung die verschiedene Strukturen von Interesse angefärbt und in konfokalmikroskopischen Aufnahmen ausgewertet. Dabei wurden sowohl die Haarzellen der Kochlea spezifisch angefärbt als auch ihre synaptischen Bänder, afferente Nervenfasern und Spiralganglienneurone.

Im Vergleich zu Otof-Wildtyp-Mäusen zeigen Otof-Knockout-Mäuse einen deutlich gravierenderen Verlust sowohl von IHZ als auch von ÄHZ, der zunächst langsam von basal ausgehend voranschreitet und sich später auch von apikal in Richtung basal ausbreitet. Bei Otof-Wildtyp-Mäusen beobachteten wir einen mäßigen Verlust von Haarzellen über den Zeitverlauf. In 24 Wochen alten Tieren waren IHZ zum größten Teil erhalten, erst bei 48 Wochen alten Tieren sah man einen deutlichen Zellverlust, der vor allem basal ausgeprägt war. Die ÄHZ waren früher betroffen und zeigten schon mit 24 Wochen basale Verluste. Mit 
A

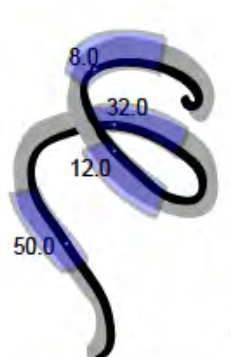

B $\mathrm{IHZ}$

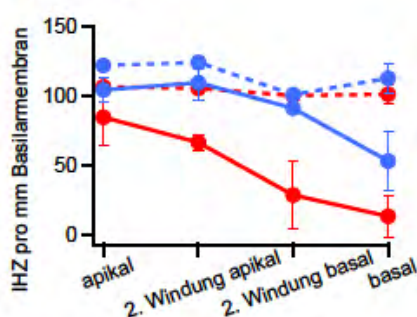

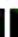
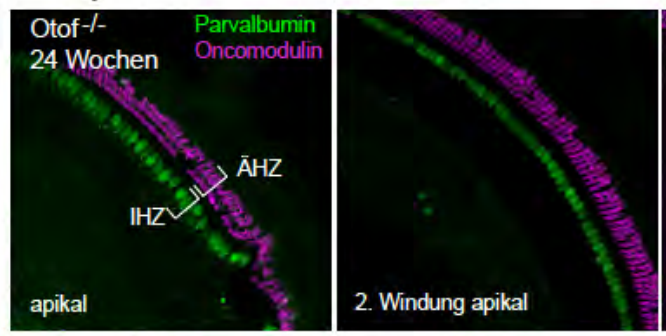

Otof $+1+$
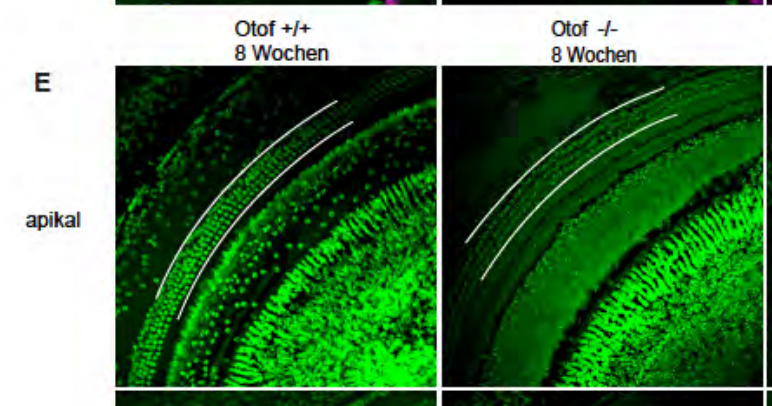

2. Windung basal

c $\ddot{A} H \mathrm{Z}$
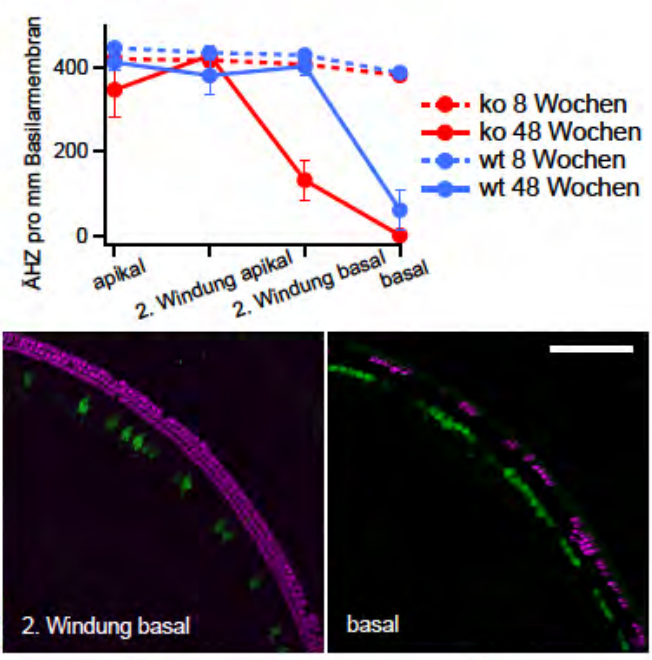

Otof $+1+$
48 Wochen

Otof $-1-$
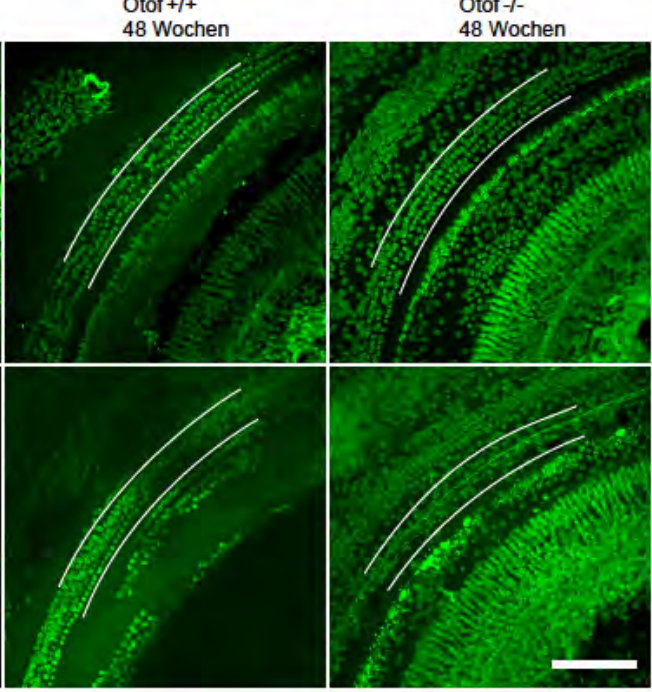

Abbildung 3.4 - Degeneration der IHZ und ÄHZ von basal nach apikal: A) Schema der Aufnahmeorte für die Quantifizierung der IHZ und ÄHZ mit Frequenz in kHz nach kochleärer Lokalisation, Ref. s. Abb.2.1 , B) IHZ und C) ÄHZ entlang des Corti-Organs von Otof-Knockoutund Otof-Wildtyp Tieren im Alter von 8 und 48 Wochen (8 Wochen: $w t: n=2, k o: n=4$; 48 Wochen: $w t: n=4, k o: n=4)$; D) Degeneration von IHZ und ÄHZ schreitet von basal nach apikal voran, Otof-Knockout mit 24 Wochen, IHZ sind mit Parvalbumin gefärbt, ÄHZ mit Oncomodulin; E) Apikale und basale Windungen von Otof-Wildtyp und Otof-Knockout mit 8 und 48 Wochen, Hoechstfärbung der Nuclei; Maßstab: $100 \mu \mathrm{m}$ 
Tabelle 3.1 - IHZ und ÄHZ Zellzahlen pro mm Basilarmembran von 8 und 48 Wochen alten OtofKnockout- und Otof-Wildtyp-Mäusen; Messwert \pm SEM; Tierzahlen entsprechen Abb. 3.4B) C) Wenn nur ein Messwert in der Gruppe verwendbar war, ist hier kein \pm SEM angegeben

\begin{tabular}{|c|c|c|c|c|c|}
\hline & & \multicolumn{4}{|c|}{ Otof $^{+/+}$} \\
\hline \multirow{3}{*}{ IHZ } & & apikal & 2. Wind. apikal & 2. Wind. basal & basal \\
\hline & $8 \mathrm{Wo}$ & $121.6 \pm 1.1$ & $123.8 \pm 4.3$ & 100.7 & $112.5 \pm 10.8$ \\
\hline & $48 \mathrm{Wo}$ & $104.0 \pm 8.5$ & $109.2 \pm 12.6$ & $90.8 \pm 0.9$ & $52.9 \pm 21.0$ \\
\hline \multirow{2}{*}{ ÄHZ } & $8 \mathrm{Wo}$ & $445.9 \pm 4.2$ & $434.5 \pm 16.4$ & $428.4 \pm 2.0$ & 386.7 \\
\hline & $48 \mathrm{Wo}$ & $411.2 \pm 19.5$ & $380.2 \pm 45.6$ & $401.5 \pm 23.2$ & $59.8 \pm 47.3$ \\
\hline & & \multicolumn{4}{|c|}{ Otof $^{-/-}$} \\
\hline \multirow{2}{*}{ IHZ } & $8 \mathrm{Wo}$ & $106.3 \pm 2.9$ & $105.2 \pm 1.6$ & $100.0 \pm 4.6$ & $100.9 \pm 7.0$ \\
\hline & $48 \mathrm{Wo}$ & $84.3 \pm 19.7$ & $66.2 \pm 5.6$ & $28.4 \pm 24.0$ & $13.2 \pm 15.2$ \\
\hline \multirow{2}{*}{ ÄHZ } & $8 \mathrm{Wo}$ & $419.4 \pm 6.7$ & $416.5 \pm 14.7$ & $406.6 \pm 6.3$ & $380.7 \pm 10.1$ \\
\hline & $48 \mathrm{Wo}$ & $346.1 \pm 64.1$ & $427.6 \pm 13.6$ & $131.1 \pm 47.4$ & $0.0 \pm 0.0$ \\
\hline
\end{tabular}

48 Wochen waren bei fast allen Tieren basal keine ÄHZ zu finden, apikal davon waren die Zellreihen aber gut erhalten (s. Abb. 3.4).

Bei Otof-Knockout-Tieren im Alter von 8 Wochen scheint das Corti-Organ auf den ersten Blick vollständig intakt und nicht von Wildtyp-Tieren zu unterscheiden. Bei Quantifizierung der Haarzelldichte fällt allerdings eine mäßige Reduktion der IHZ-Zellzahlen auf (s. Tbl. 3.1). Bis 24 Wochen wird der Verlust von Haarzellen dann ausgeprägter und ist deutlich als Lücken in den Reihen der äußeren und inneren Haarzellen zu sehen (s. Abb. 3.4). Bei den ÄHZ ist meist zuerst die äußerste Reihe betroffen. Otof Wildtyp Mäuse zeigen im Alter von 48 Wochen einen Verlust von ca. 50\% der inneren Haarzellen im basalen Abschnitt des CortiOrgans. Die apikale und 2. Windung sind nur wenig betroffen mit ca. 10\% Verlust. OtofKnockout-Mäuse sind dagegen deutlich ausgeprägter von Haarzelldegeneration betroffen, Am stärksten ist der Effekt basal mit $>80 \%$ und am geringsten in der apikalen Windung mit ca. $20 \%$ (s. Abb.3.4).

Auch die äußeren Haarzellen der Otof-Knockout-Mäuse sind stärker betroffen als die der 

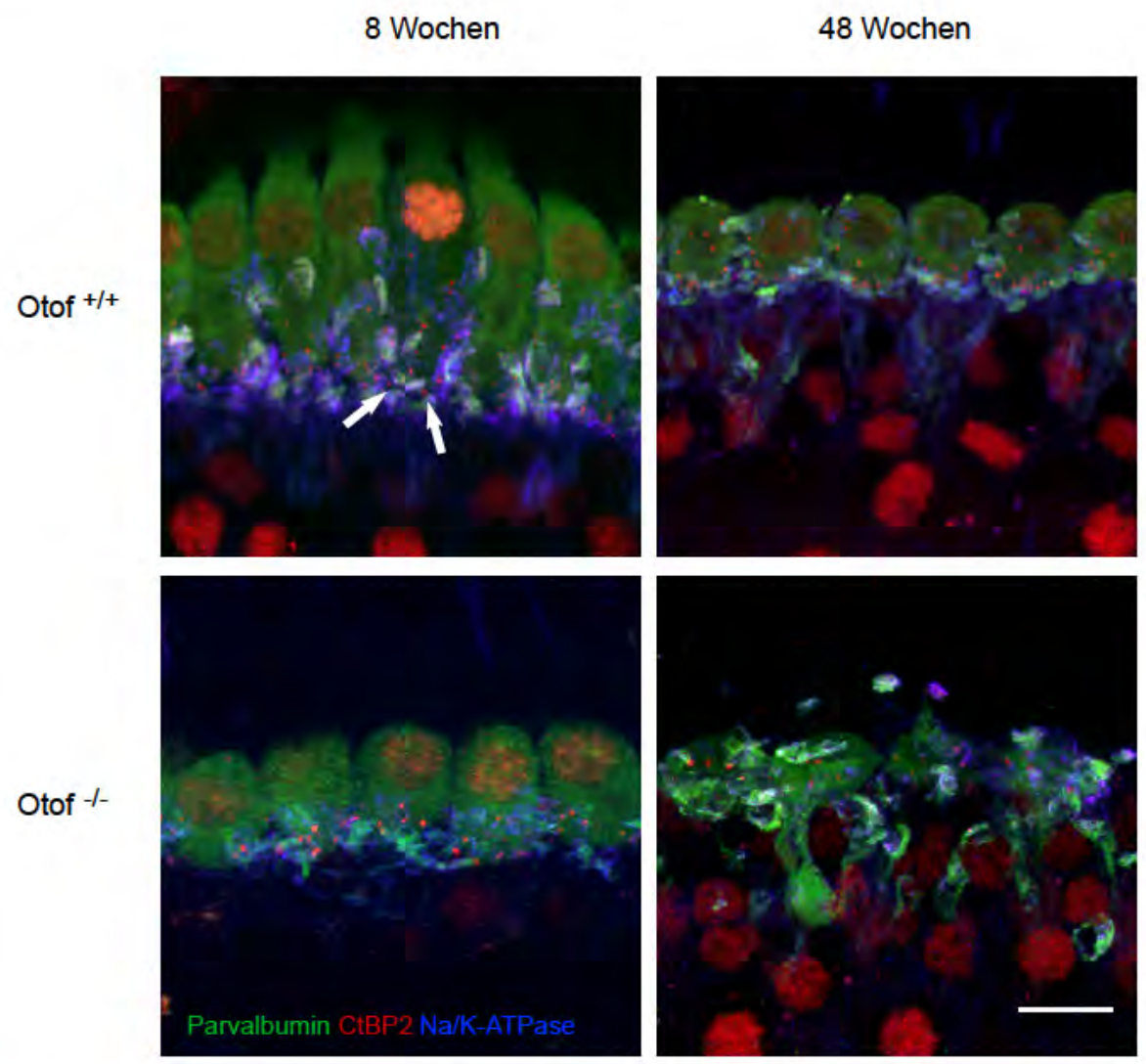

Abbildung 3.5 - Innere Haarzellen in Otof-Knockout und Otof-Wildtyp im Alter von 8 Wochen und 48 Wochen. Innere Haarzellen sind mit Parvalbumin gefärbt, Afferenzen mit Na/K-ATPase und synaptische Bänder mit CtBP2. Pfeile zeigen auf CtBP2-gefärbte synaptische Bänder; Aufnahmen aus der Region der basalen 2. Windung. Maßstab: $10 \mu \mathrm{m}$

Otof-Wildtyp-Mäuse. Mit 48 Wochen waren bei keinem Tier basal ÄHZ zu finden und auch basal in der 2. Windung und ganz apikal sind Verluste zu erkennen. Im apikalen Abschnitt der 2. Windung, ca bei $16-22 \mathrm{kHz}$, ist die Anzahl der ÄHZ dagegen nicht im Vergleich zu 8 Wochen alten Tieren reduziert. Beim Otof-Wildtyp zeigt sich ausschließlich basal ein erheblicher Verlust von ÄHZ (s. Abb. 3.4 und Tbl. 3.1). Bei älteren, 24-48 Wochen alten Tieren waren die Präparationsbedingungen erheblich erschwert, einmal durch die Verknöcherung der Kochlea, aber auch, da die Corti-Organ-Abschnitte bevorzugt in Regionen des Haarzellverlustes zu zerreißen schienen. Diese Präparate konnten nicht zur Quantifizierung verwendet werden und möglicherweise wird dadurch hier der Verlust von Haarzellen noch systematisch unterschätzt.

Während die Morphologie der einzelnen inneren Haarzelle im Otof-Knockout im Alter von 

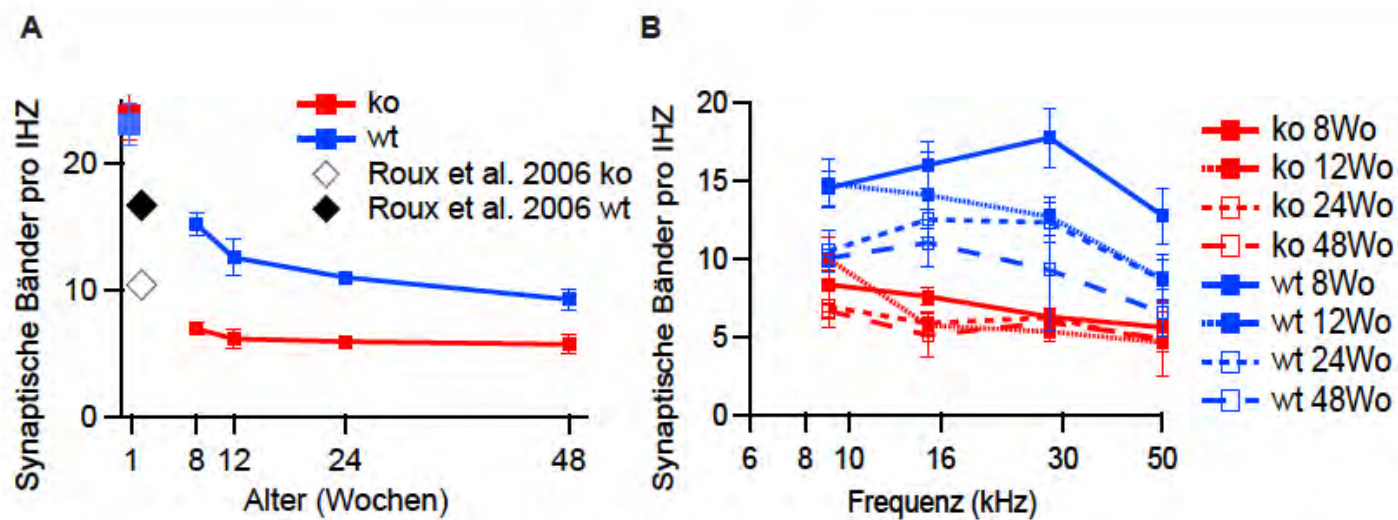

\begin{abstract}
Abbildung 3.6 - Anzahl der synaptischen Bänder pro IHZ im Zeitverlauf und tonotopisch verteilt 6 Tage: ko: $n=65$ Haarzellen, $N=2$ Tiere; wt $n=50, N=2 ; 8$ Wochen: ko: $n=215, N=7$; wt: $n=146, N=5 ; 12$ Wochen: ko: $n=140, N=5$; wt: $n=97, N=3 ; 24$ Wochen: ko: $n=203$, $N=8$, wt: $n=139, N=4 ; 48$ Wochen: $k o: n=102, N=4 ; w t: n=98, N=4$ Anzahl der synaptischen Bändern bei Otof-Knockout und Wildtyp im Alter von 15 Tagen aus Roux et al. 2006
\end{abstract}

8 Wochen in den hier verwendeten Färbungen nicht vom Otof-Wildtyp zu unterscheiden ist, scheint die Reihe der IHZ auf der Basilarmembran doch schon geringfügig in ihrer Dichte reduziert zu sein, noch ohne Lücken aufzuweisen, s. Abb 3.6. Im Alter von 48 Wochen zeigen sich in allen Otof-Knockout-Tieren große IHZ Lücken auf der Basilarmembran und deutliche Auffälligkeiten der Haarzellen, die in Otof-Wildtyp-Tieren gleichen Alters nicht beobachtet wurden. Die verbleibenden IHZ in den basalen Abschnitten sind deformiert und verbreitert (s. Abb. 3.5).

Ein deutlicher Unterschied besteht in der Anzahl von synaptischen Bändern in OtofKnockout und Otof-Wildtyp, wie in Abb. 3.5 und Abb. 3.6 zu sehen. Wie bereits beschrieben (Roux et al. 2006) ist am 6. postnatalen Tag die Anzahl der synaptischer Bänder pro IHZ in Otof-Knockout (23,74 $\pm 1,8$ pro IHZ) und Otof-Wildtyp (23,07 $\pm 1,6$ pro IHZ) übereinstimmend. Im Alter von acht Wochen ist die Anzahl im Otof-Knockout auf 5-7 pro Haarzelle reduziert und bleibt dann aber bis 48 Wochen in allen verwendeten Tieren konstant. Der Otof-Wildtyp zeigt im Alter einen stetigen Verlust, der auch schon zwischen 8 und 12 Wochen alten Tieren basal zu erkennen ist und sich nach apikal ausbreitet. Bei dem Verlust der Bändersynapsen fiel keine Präferenz der neuralen oder abneuralen Seite auf, es schienen allerdings eher größere CtBP2 Punkte in der Nähe des basalen Pols erhalten zu bleiben s. 
Tabelle 3.2 - Bändersynapsen pro IHZ von Otof-Knockout und Otof-Wildtyp-Mäusen von 8-48 Wochen; Messwert \pm SEM; Tierzahlen entsprechen Abb. 3.6

\begin{tabular}{cccccc}
\hline & apikal & 2. Wind. apikal & 2. Wind. basal & basal \\
\hline 8 Wo & $14.5 \pm 1.1$ & $16 \pm 1.5$ & $17.7 \pm 1.9$ & $12.7 \pm 1.8$ \\
Otof $^{+/+}$ & $12 \mathrm{Wo}$ & $14.8 \pm 1.6$ & $14.1 \pm 2.7$ & $12.7 \pm 1.2$ & $8.7 \pm 1.5$ \\
& $24 \mathrm{Wo}$ & $10.5 \pm 1.4$ & $12.5 \pm 0.6$ & $12.3 \pm 1.3$ & $8.6 \pm 1.3$ \\
$48 \mathrm{Wo}$ & $10.0 \pm 0.5$ & $11.0 \pm 1.5$ & $9.3 \pm 3.9$ & $6.5 \pm 1.5$ \\
\hline & $8 \mathrm{Wo}$ & $8.4 \pm 1$ & $7.6 \pm 0.6$ & $6.3 \pm 0.5$ & $5.6 \pm 0.9$ \\
Otof $^{-/-}$ & $12 \mathrm{Wo}$ & $10.0 \pm 1.4$ & $5.7 \pm 0.7$ & $5.3 \pm 0.6$ & $4.6 \pm 0.6$ \\
& $24 \mathrm{Wo}$ & $6.9 \pm 0.6$ & $5.9 \pm 0.3$ & $6.2 \pm 0.6$ & $4.7 \pm 1$ \\
$48 \mathrm{Wo}$ & $6.7 \pm 0.5$ & $5.1 \pm 1.4$ & $5.9 \pm 0.7$ & $4.9 \pm 2.4$ \\
\hline
\end{tabular}

Abb. 3.5, die Größe und Lokalisation wurde allerdings nicht genauer analysiert.

Die Dichte der Zellkörper bipolarer Spiralganglienneurone im Rosenthalkanal ist im Alter von 8 Wochen in Otof-Wildtyp und Otof-Knockout vergleichbar. Im Alter von 48 Wochen zeigen Otof-Wildtyp einen geringen basalen Verlust und Otof-Knockout-Mäuse einen basalen und apikalen Verlust. Otof-Knockout-Tiere scheinen von größerem Verlust betroffen zu sein, wobei der Unterschied nicht signifikant ist. Bei Otof-Knockout-SGN wurde in mehreren Tieren in der apikalen Windung eine Verklumpung der SGN-Zellkörper gesehen, die bei den den gleichaltrigen Wildtyp-Tieren nicht vorkam (s. Abb. 3.7 C). 

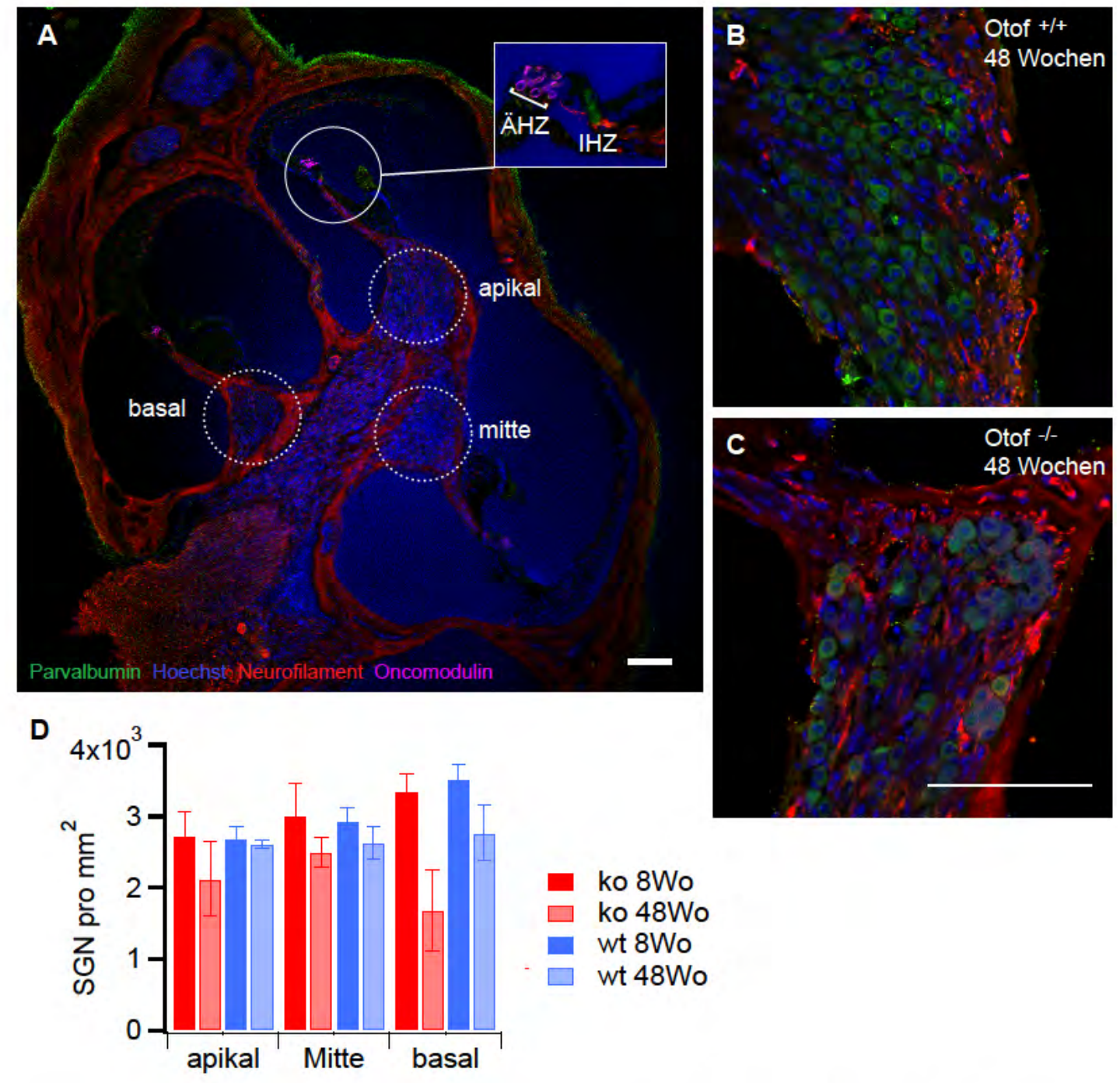

Abbildung 3.7 - A)Kryoschnitt einer Kochlea mit Anschnitt der Scalae, des Modiolus und des CortiOrgans (s. Vergrößerung) - Maßstab $100 \mu \mathrm{m}$; B) und C) Spiralganglienneurone im Rosenthalkanal der apikalen Windung - Maßstab $100 \mu \mathrm{m}$ D) Spiralganglienneurone in wt und ko mit 8 Wochen und 48 Wochen 8 Wochen: wt:n=5, ko:n=3; 48 Wochen: $w t: n=3, k o: n=4$ 


\subsection{Lärmempfindlichkeit der Otof-Knockout-Mäuse}

\subsection{1 Äußere Haarzellfunktion nach Lärmtrauma}

Um einen Unterschied in der Lärmempfindlichkeit zwischen Otof-Knockout-Mäusen und Otof-Wildtyp-Mäusen zu testen wurden Wurfgeschwister im Alter von 8 Wochen zwei unterschiedlichen Lärmtraumaversuchsreihen unterzogen. Beide Gruppen wurden entweder 15 Minuten mit $103 \mathrm{~dB}$ 4-16 kHz Breitbandlärm beschallt, oder 2 Stunden mit $120 \mathrm{~dB}$ 4-16 kHz Breitbandlärm. Bei allen Tieren wurden vor der Beschallung und Tag 1 und 3 nach Lärmtrauma akustisch evozierte Potentiale und Distorsionsprodukte otoakustischer Emissionen gemessen.

Bei einem leichten 103 dB-Lärmtrauma über 15 min zeigte sich bei den Wildtypen eine Hörschwellenanhebung, betont in den hohen Frequenzen von 16 kHz bis 32 kHz (s. Abb.3.8). Die Hörschwellenanhebung ist am ersten Tag nach Lärmtrauma, ca. 24 h später, am stärksten ausgeprägt, mit dem größten Schwellenschwund von $45.8 \mathrm{~dB} \pm 3.0$ bei $16 \mathrm{kHz}$. Schwellen erholten sich bis zum 3. Tag leicht, vor allem bei den tieferen Frequenzen 6-12 kHz und blieben gehoben bei $24-32 \mathrm{kHz}$. Nach intensivem Lärmtrauma mit $120 \mathrm{~dB}$ für zwei Stunden zeigte sich eine starke Hörschwellenhebung, am stärksten ausgeprägt bei $16 \mathrm{kHz}$ mit 64.6 $\mathrm{dB} \pm 5.8$, aber auch im Unterschied zum gemäßigten Lärmtrauma bei niedrigen Frequenzen stark ausgeprägt. Die Amplitude der Welle I zeigte eine deutliche Reduktion nach beiden Lärmtraumaparadigmen, die sich von bis zum 3. Tag nach Lärmtrauma kaum erholt (s. Abb. $3.8 \mathrm{~B}))$.

Die DPOAE reagieren auf das Lärmtrauma ebenfalls mit einer deutlichen Reduktion der Amplituden (s. Abb. 3.9). Bei leichtem Lärmtrauma sind die Amplituden bei F2: 11.3, 16 und $22.6 \mathrm{kHz}$ betroffen, wobei die Knockout-Mäuse bei $16 \mathrm{kHz}$ etwas weniger betroffen zu sein scheinen. Nach starkem Lärmtrauma sind die Amplituden in beiden Gruppen über alle Testfrequenzen reduziert. 

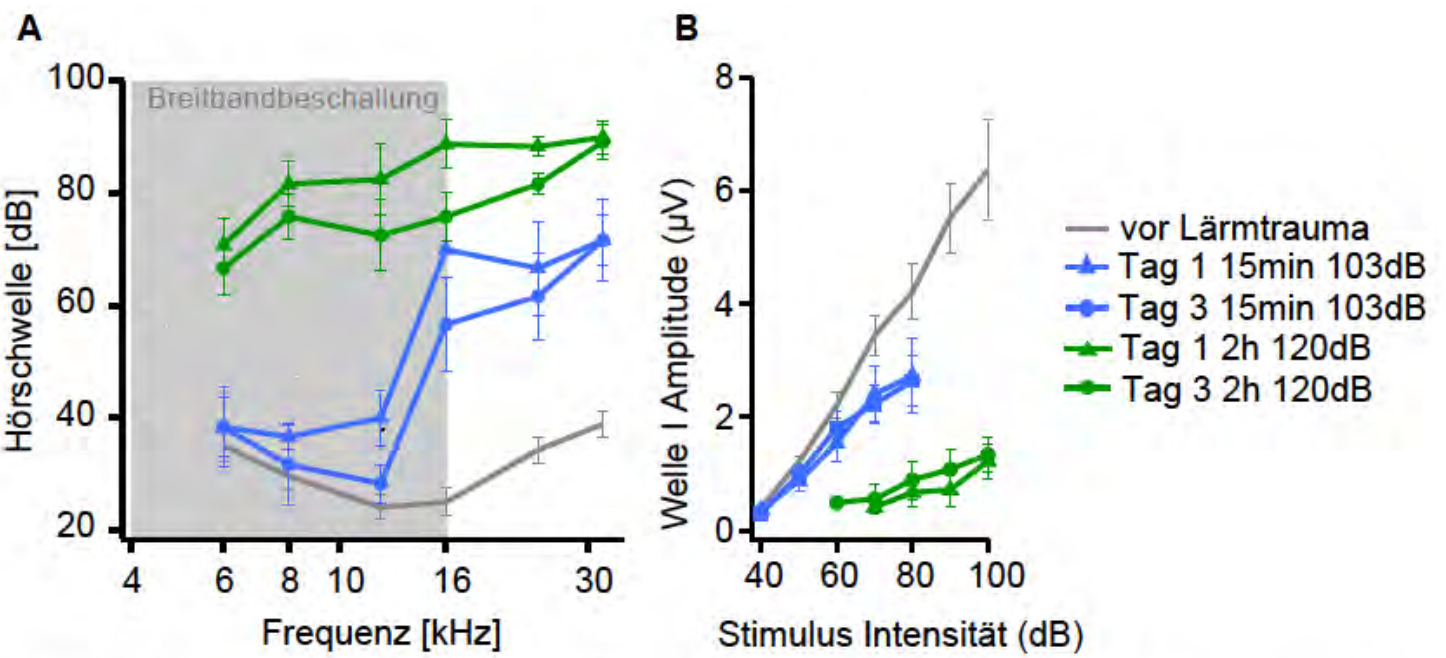

Abbildung 3.8 - A) Hörschwellen und B) Welle I-Amplituden der Otof-Wildtyp-Mäuse vor und nach Beschallung mit leichtem oder schwerem Lärmtrauma; Frequenzband des Breitbandlärms ist grau unterlegt wt vor Lärmtrauma: $n=14$, leichtes Lärmtrauma: $w t$ t $n=6$, schweres Lärmtrauma: Kontrollen: wt: $n=4$ het: $n=2$ s. Kapitel 2.1

A unbeschallt

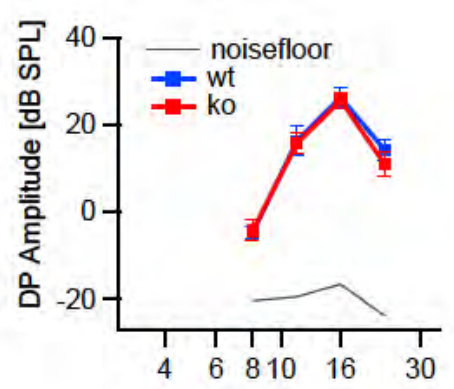

F2 Stimulusfrequenz [ $\mathrm{kHz}]$
B leichtes Lärmtrauma

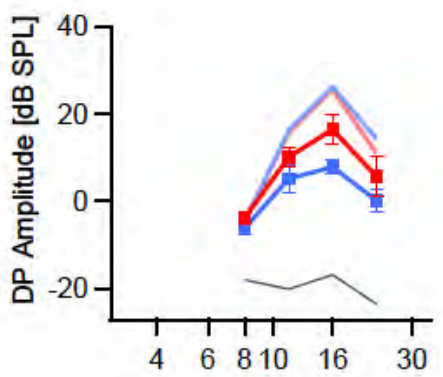

F2 Stimulusfrequenz $[\mathrm{kHz}]$
C schweres Lärmtrauma

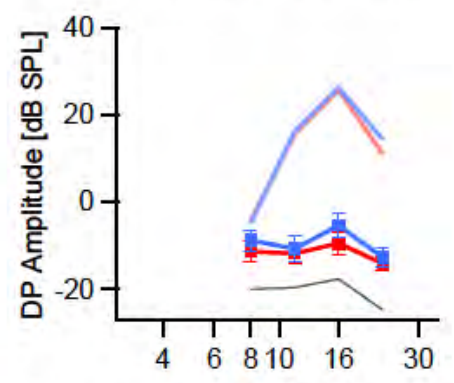

F2 Stimulusfrequenz [kHz]

Abbildung 3.9 - DP-Amplituden bei F2:60 dB A) vor Lärmtrauma $w t: n=12$, $k o: n=12$, B) nach leichtem Lärmtrauma ko:n=6, wt:n=6und C) nach schwerem Lärmtrauma ko: $n=6$, Kontrollen: $w t: n=4$, het: $n=2$ die Amplituden vor Lärmtrauma sind in B) und C) zum Vergleich als helle Linien dargestellt 


\subsubsection{Schweres Lärmtrauma führt zu Verlust von äußeren Haarzellen in Otof-Knockout und Otof-Wildtyp}

Nach leichtem Lärmtrauma ist kein Unterschied der IHZ- und ÄHZ-Zellzahlen zwischen Otof-Knockout und Otof-Wildtyp unbeschallt und nach Lärmtrauma auszumachen (s. Abb.3.10).

Auch nach schwerem Lärmtrauma sind die IHZ nicht im Überleben beeinträchtigt. Die ÄHZ zeigen dagegen in Otof-Knockout und Otof-Wildtyp einen gleich ausgeprägten basalen Verlust um ca. $60 \%$.

Wie in Kapitel 3.1.2 auf Seite 24 beschrieben, besitzen Otof-Knockout-Mäuse im Alter von 8 Wochen nur 30-50\% der Anzahl von synaptischen Bänder pro IHZ verglichen mit Wildtyp-Mäusen. Dieses Ergebnis ist auch bei den unbeschallten Kontrolltieren zu erkennen (s. Abb.3.12 B)). Nach einem leichten Lärmtrauma von 103 dB Breitbandlärm über 15 min ist bei den Otof-Wildtyp-Tieren eine Reduktion der synaptischen Bänder bei $30 \mathrm{kHz}$ und $50 \mathrm{kHz}$ zur erkennen, gleichzeitig ein Anheben der Hörschwellen bei $16 \mathrm{kHz}, 24$ $\mathrm{kHz}$ und $32 \mathrm{kHz}$. In den Otof-Knockout-Tieren ist keine Veränderung zu erkennen. Nach schwerem Lärmtrauma sind die synaptischen Bänder im Otof-Wildtyp über alle Regionen stark reduziert, besonders bei $30 \mathrm{kHz}$ und $50 \mathrm{kHz}$ um >70\%. Im Otof-Knockout ist die Anzahl weithin unverändert (s. Tabelle 3.4). Desweiteren beobachteten wir nach Lärmtrauma in Otof-Wildtyp-Mäusen vermehrt innere Haarzellen mit schwacher Parvalbuminfärbung und starker CtBP2-Kernfärbung (s. Abb.3.12 C), die wir als Anzeichen von Apoptose mit Kernkondensation interpretierten. Die Parvalbuminfärbung gelang nach Lärmtrauma trotz des gleichem Färbeprotokolls bei allen Otof-Wildtyp-Tieren wesentlich schlechter und zeigten in den Aufnahmen schwächere Fluoreszenz (s. Abb. 3.12 E). 

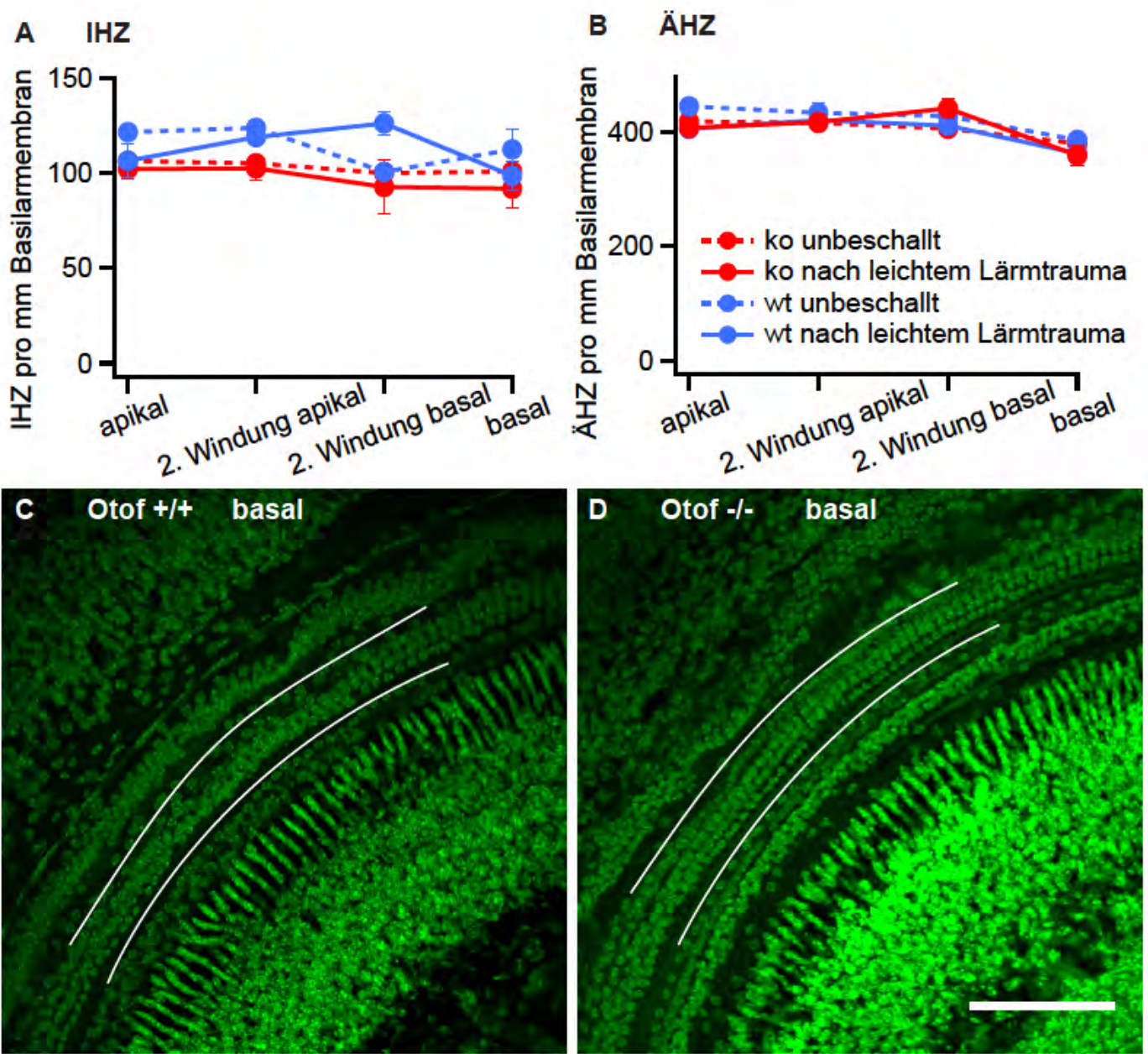

Abbildung 3.10 - A) IHZ und B) ÄHZ-Anzahl pro mm Basilarmembran nach leichtem Lärmtrauma (unbeschallt: wt: $n=2$, ko: $n=4$; leichtes Lärmtrauma: wt: $n=4$, ko: $n=5$ ), C) Nucleifärbung von Otof-Wildtyp und D) Otof-Knockout in der basalen Windung, Maßstab 100 $\mu \mathrm{m}$ 

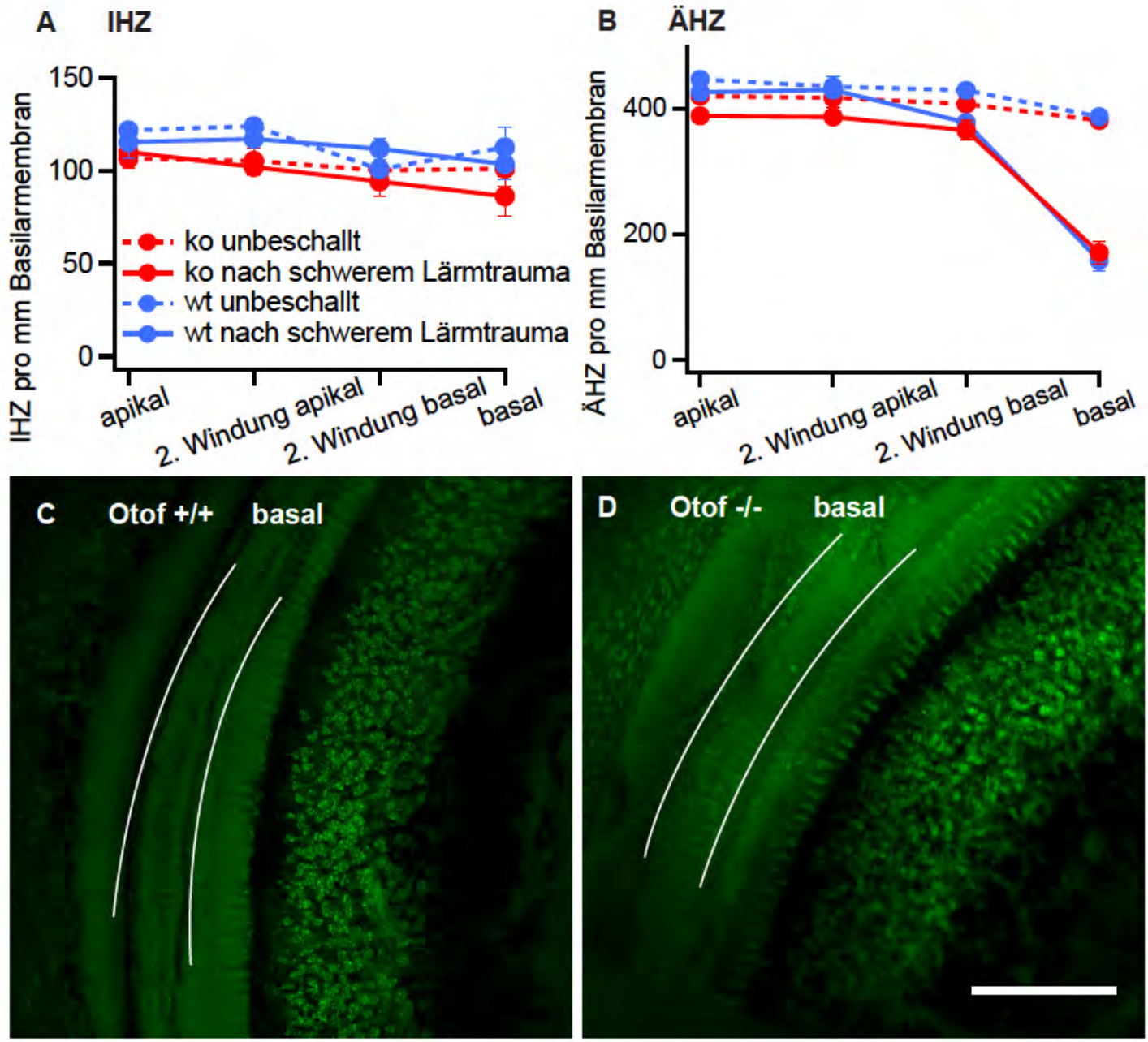

Abbildung 3.11 - A)IHZ und B)ÄHZ pro mm Basilarmembran von Otof-Wildtyp und Otof-Knockout nach schwerem Lärmtrauma (unbeschallt: $w t: n=2, k o: n=4$, schweres Lärmtrauma: wt: $n=6, k o: n=6$ ), C) Nucleifärbung von Otof-Wildtyp und D) Otof-Knockout in der basalen Windung, Maßstab $100 \mu \mathrm{m}$ 
Tabelle 3.3 - IHZ- und ÄHZ-Zellzahlen pro mm Basilarmembran schwer und leicht lärmtraumatisierter Otof-Knockout- und Otof-Wildtyp-Mäusen; Messwert \pm SEM; Tierzahlen entsprechen Abb. 3.10 und Abb. 3.11 Wenn nur ein Messwert in der Gruppe verwendbar war ist hier kein \pm SEM angegeben

\begin{tabular}{|c|c|c|c|c|c|}
\hline & & \multicolumn{4}{|c|}{ Otof $^{+/+}$} \\
\hline & & apikal & 2. Wind. apikal & 2. Wind. basal & basal \\
\hline & unbeschallt & $121.6 \pm 1.1$ & $123.8 \pm 4.3$ & 100.7 & $112.5 \pm 10.8$ \\
\hline \multirow[t]{3}{*}{ IHZ } & leichtes Lärmtrauma & $106.5 \pm 8.8$ & $118.9 \pm 1.0$ & $126.2 \pm 5.9$ & $98.6 \pm 7.8$ \\
\hline & schweres Lärmtrauma & $115.2 \pm 3.3$ & $116.9 \pm 2.9$ & $111.7 \pm 8.9$ & $103.3 \pm 9.5$ \\
\hline & unbeschallt & $445.9 \pm 4.2$ & $434.5 \pm 16.4$ & $428.4 \pm 2.0$ & 386.7 \\
\hline \multirow[t]{4}{*}{ ÄHZ } & leichtes Lärmtrauma & $406.3 \pm 13.6$ & $421.3 \pm 13.6$ & $412.0 \pm 4.0$ & $363.4 \pm 15.9$ \\
\hline & schweres Lärmtrauma & $425.5 \pm 7.8$ & $429.2 \pm 11.3$ & $377.1 \pm 63.6$ & $157.8 \pm 83.1$ \\
\hline & & \multicolumn{4}{|c|}{ Otof $^{-/-}$} \\
\hline & unbeschallt & $106.3 \pm 2.9$ & $105.2 \pm 1.6$ & $100.0 \pm 4.6$ & $100.9 \pm 7.0$ \\
\hline \multirow[t]{3}{*}{ IHZ } & leichtes Lärmtrauma & $102.1 \pm 5.0$ & $102.5 \pm 6.3$ & $92.7 \pm 14.1$ & $91.8 \pm 9.8$ \\
\hline & schweres Lärmtrauma & $109.9 \pm 7.7$ & $101.9 \pm 4.5$ & $94.0 \pm 6.0$ & $86.1 \pm 13.1$ \\
\hline & unbeschallt & $419.4 \pm 6.7$ & $416.5 \pm 14.7$ & $406.6 \pm 6.3$ & $380.7 \pm 10.1$ \\
\hline \multirow[t]{2}{*}{ ÄHZ } & leichtes Lärmtrauma & $407.7 \pm 7.6$ & $418.2 \pm 7.2$ & $442.3 \pm 15.9$ & $359.9 \pm 18.6$ \\
\hline & schweres Lärmtrauma & $388.0 \pm 16.5$ & $386.2 \pm 23.0$ & $364.9 \pm 36.1$ & $170.0 \pm 79.9$ \\
\hline
\end{tabular}



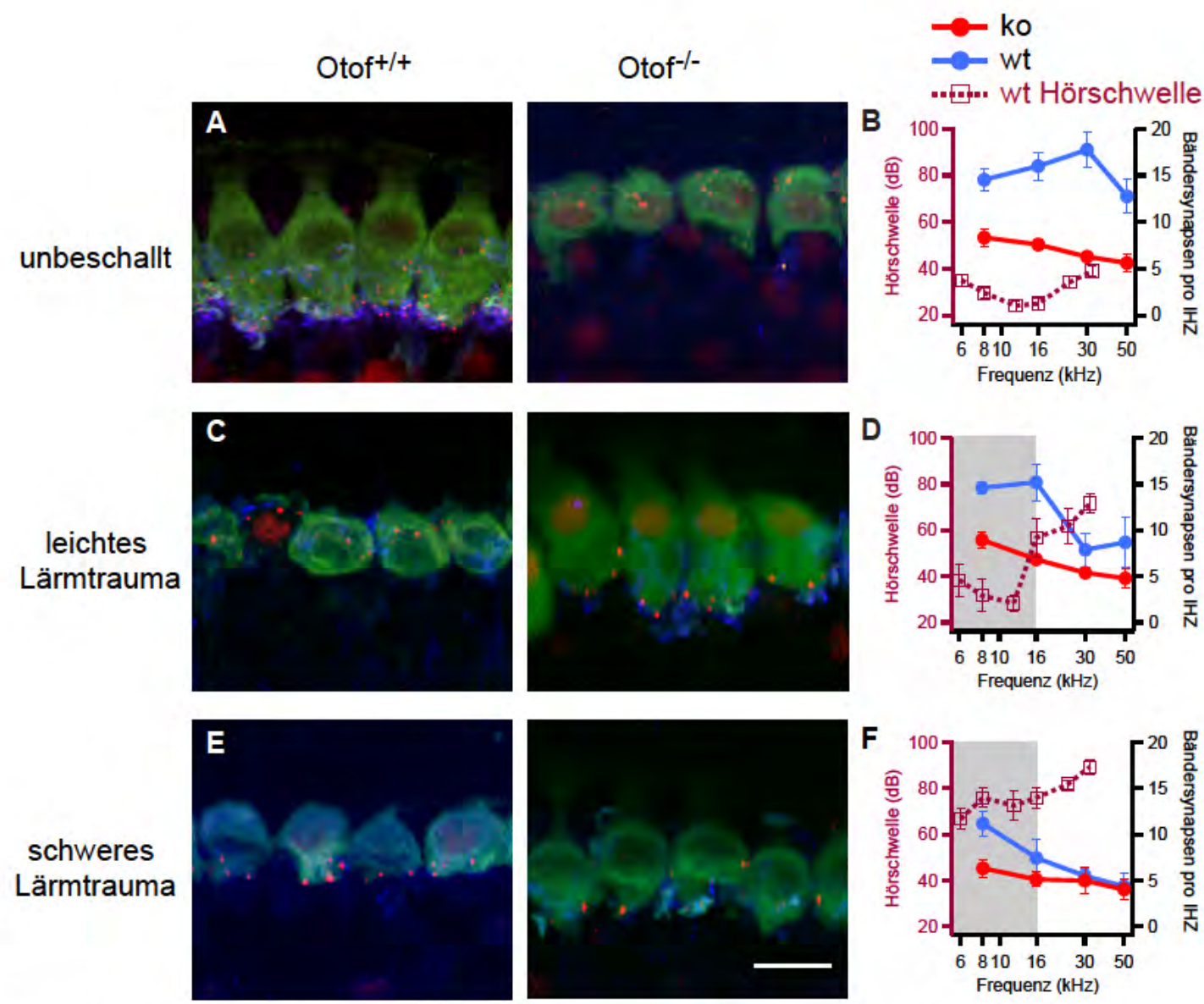

Abbildung 3.12 - Bändersynapsen in Otof-Knockout und Otof-Wildtyp A), C), E) Färbung der Inneren Haarzellen mit Parvalbumin (grün), synaptische Bänder mit CtBP2 (rot) und afferente Nervenfasern mit Na/K-ATPase (blau); Maßstab 10 $\mu m$; B), D) und F) Anzahl der synaptischen Bänder und Hörschwellen der Hirnstammaudiometrie, Frequenzband des Breitbandlärms ist grau unterlegt; (unbeschallt: wt: $n=5, k o: n=7$; leichtes Lärmtrauma: wt: $n=5$, ko: $n=5$; schweres Lärmtrauma: $w t: n=6, k o: n=6$ ) 
Tabelle 3.4 - Bändersynapsen pro IHZ von Otof-Knockout- und Otof-Wildtyp-Mäusen unbeschallt, nach leichtem Lärmtrauma und nach schwerem Lärmtrauma; Messwert \pm SEM; Tierzahlen entsprechen denen in Abb. 3.12

\begin{tabular}{llccccc}
\hline & apikal & 2. Wind. apikal & 2. Wind. basal & basal \\
\hline \multirow{2}{*}{ Otof $^{+/+}$} & unbeschallt & $14.5 \pm 1.1$ & $16 \pm 1.5$ & $17.7 \pm 1.9$ & $12.7 \pm 1.8$ \\
& leichtes Lärmtrauma & $14.6 \pm 0.7$ & $15.2 \pm 2$ & $7.9 \pm 1.8$ & $8.7 \pm 2.6$ \\
& schweres Lärmtrauma & $11.2 \pm 1.3$ & $7.4 \pm 2$ & $5.5 \pm 0.8$ & $4.4 \pm 1.4$ \\
\hline \multirow{2}{*}{ Otof $^{-/-}$} & leichtes Lärmtrauma & $8.9 \pm 0.9$ & $6.8 \pm 0.4$ & $5.4 \pm 0.4$ & $4.8 \pm 1$ \\
& unbeschallt & schweres Lärmtrauma & $6.3 \pm 0.9$ & $5.1 \pm 0.7$ & $5 \pm 1.7$ & $4 \pm 1.2$ \\
\hline
\end{tabular}




\section{Diskussion}

\subsection{Frühe altersabhängige Degeneration in Abwesenheit von Otoferlin}

Beeinträchtigungen des Hörvermögens gehören weltweit zu den häufigsten chronischen Einschränkungen und beeinflussen das Leben der Betroffenen stark. Mittlerweile wurden hervorragende Hilfsmittel entwickelt, z. B. das Kochlea Implantat. Da dabei die Hörnervenneurone direkt durch Elektroden erregt werden sollen, ist die Vorraussetzung für ein gutes Resultat ein möglichst intakter Hörnerv. Auch für mögliche zukünftige Therapien, z.B. Stammzell- und Gentherapie, ist eine erhaltene Integrität des Hörnerven und auch der Haarzellen des Innenohrs essentiell. Daher ist das Wissen über Ablauf und Gründe für die Degeneration dieser Strukturen bei den verschiedenen Taubheitsformen sehr wichtig. Sowohl bei angeborenen Taubheitsformen als auch bei erworbenen Taubheitsformen wurden schon sehr schnelle und starke Degenerationsverläufe beschrieben. Hier beobachteten wir die Degeneration des Corti-Organs in einem Mausmodell für die menschliche Taubheitsform DFNB9, die auf Mutationen im Gen für Otoferlin beruht.

Die Abwesenheit von Otoferlin verhindert fast vollständig die kalziumabhängige Neurotransmitterausschüttung an den Bändersynapsen der IHZ und verursacht somit schwere angeborene Taubheit in Menschen (Yasunaga et al. 1999) und im Mausmodell (Roux et al. 2006, Pangršič 2010, 2012). Im ersten Teil dieser Arbeit sollte untersucht werden, welchen Einfluss das Fehlen der synaptischen Transmission bei Otof-Knockout-Mäusen auf die funktionale und morphologische Integrität des Corti-Organs hat.

Dazu ermittelten wir die Zahl der IHZ und ÄHZ sowie die Zahl der synaptischen Verbindungen zwischen IHZ und Hörnervenfasern und den Verlust von Spiralganglienneuronzellkörpern. Ein methodisches Problem unserer Studie bezüglich der Quantifikation von 
Bandsynapsen ist die fehlende Kontrolle mithilfe eines postsynaptischen immunhistochemischen Markers, um beide Seiten von intakten Synapsen und nicht nur die präsynaptische Struktur des synaptischen Bandes identifizieren zu können. Hier können wir deshalb keine sichere Aussage treffen über eine mögliche Dissoziation von synaptischen Bändern und Postsynapsen oder die Anzahl von verwaisten synaptischen Bändern, von Roux et al. 2006 bei $20 \%$ der Otof-Knockout-Synapsen im Alter von 15 Tagen beschrieben. Allerdings erlaubt die hier durchgeführte Zytoplasma- und Neuronenfärbung eine recht verlässliche Identifikation von zellmembranständigen und Neuronen-assoziierten CtbP2-positiven synaptischen Bändern. Zuletzt sind unsere Ergebnisse in Quantifikation der Synapsenzahl anhand der hier durchgeführten Färbungen mit früheren Untersuchungen, die den Vorteil von postsynaptischen Färbungen oder elektronenmikroskopische Bildern hatten, nahezu identisch (Meyer et al. 2009, Stamataki et al. 2006). Auch in der Otof-Mutante kommen Roux et al. 2006 zu übereinstimmenden Synapsenzahlen bei jungen Tieren. Eine statistische Testung der Synapsen- und Zellzahlen war aufgrund der vielen Gruppen und der kleinen Fallzahl in den meisten Fällen nicht sinnvoll durchführbar oder bot keine zusätzliche Aussagekraft. Trotzdem möchte ich im folgenden darlegen, welche Trends wir erfassen konnten.

Wir beobachteten die Degeneration der Kochlea von Otof-Knockout-Mäusen bis 48 Wochen postnatal. Dabei sahen wir initial bei 6 Tage alten Tieren keinen Unterschied zwischen Knockout und Wildtyp im Bezug auf Anzahl der Bändersynapsen und Morphologie der IHZ und ÄHZ. Ausgewachsene Tiere im Alter von 6-8 Wochen wurden eingehender untersucht und wir sahen eine intakte Morphologie der Kochlea: IHZ und ÄHZ waren vollständig über die gesamte Länge der Basilarmembran erhalten. Die Dichte der Spiralganglienneurone unterschied sich nicht signifikant von Otof-Wildtyp-Tieren. Die otoakustischen Emissionen waren mit normalen Amplituden vorhanden, außer einer leichten Reduktion in den höchsten Testfrequenzen. Aber bereits bei diesen jungen ausgewachsenen Tieren fiel eine deutliche Reduktion der Anzahl von synaptischen Bändern auf: Im Alter von 6 Tagen sahen wir keinen Unterschied in Knockout und Wildtyp, im Alter von 8 Wochen besaßen die Knockout-Tiere ca. die Hälfte der synaptischen Bänder der Wildtyp-Tiere. Da Roux et al. eine Reduktion der Bändersynapsen um die Hälfte schon bei 15 Tage alten Otof-Knockout-Tieren beschreibt, nehmen wir an, dass diese Reduktion zu Beginn des Hörens in Mäusen (ca. Tag 10-14) stattfindet und mit einer veränderten Ausreifung, bzw. Reorganisation von Synapsen in dieser Phase zusammenhängt (Beurg et al. 2010, Wong et al. 2013). 
Im weiteren Zeitverlauf sahen wir bei den Otof-Knockout-Mäusen zunächst eine Amplitudenreduktion der otoakustischen Emissionen, die sich intensivierte und von Bereichen der hohen Frequenzen zu niedrigfrequenten Bereichen ausbreitete. Dem folgte ein sichtbarer Verlust der ÄHZ, der mit 24 Wochen basal schon deutlich ausgeprägt war. Gleichzeitig kam es zum Verlust von IHZ, der alle Windungen betraf, aber basal am deutlichsten und in vielen Tieren vollständig war. In den ältesten untersuchten Otof-Knockout-Tieren mit 48 Wochen sahen wir einen großflächigen Haarzellverlust und dazu passende geringe Residualamplituden otoakustischer Emissionen. Die Zahl der Spiralganglienneuronzellkörper im Rosenthalkanal war basal um 50\% reduziert und auch apikal und medial leicht. Die Anzahl der synaptischen Bänder in den verbliebenden IHZ blieb dagegen konstant bei 5-7 pro Haarzelle.

\subsubsection{Einfluss der Otof-Mutation auf den Erhalt von Bändersynapsen und inneren Haarzellen}

Aufgrund der frühen und ausgeprägten Reduktion der Bändersynapsen in Otof-KnockoutMäusen erwarteten wir einen weiter voranschreitenden Verlust von synaptischen Bändern, Synapsen und Spiralganglienneuronen. Auch die bisherigen Untersuchungen an anderen Mausmodellen mit auditorischen Synaptopathien legten diese Hypothese nah (Moser et al. 2013): In $\alpha 1 D^{-/-}$-Mäusen, die keine funktionalen L-Typ-Kalziumkanäle $\mathrm{Ca}_{V} 1.3$ besitzen, ist die kalziumabhängige Exozytose ebenfalls fast komplett unterbunden, und es besteht angeborene Taubheit. Schon im Alter von einer Woche wurden bei diesen Mäusen Zeichen von Degeneration der afferenten Nervenendigungen gesehen und bis 8 Wochen ein Verlust von mehr als 50\% SGNs über alle kochleären Windungen. Dazu gesellte sich ein deutlicher IHZ- und ÄHZ-Verlust. Die Bändersynapsen in den verbliebenden Haarzellen blieben bis zum Alter von vier Wochen in normaler Anzahl erhalten und reduzierten sich danach stetig bis auf ca. 2 pro IHZ mit 28 Wochen (Nemzou N. et al. 2006, Glueckert et al. 2003).

Ein weiteres Mausmodell der beeinträchtigten synaptischen Transmission an der IHZ sind Tiere mit Defizienz des vesikulären Glutamattransporters 3. In ihnen können exozytotische Vesikel an der Bändersynapse nicht mit Glutamat gefüllt werden. Diese Mäuse zeigen eine noch frühere und schwerwiegende Degeneration der Spiralganglienneurone. Mit P10 betrifft sie das ganze Corti-Organ und bis 3 Wochen wurde eine Reduktion der Neurone im Rosenthalkanal um 50\% beobachtet. Auch das Volumen des Nucleus cochlearis ist 
bei diesen Mutanten reduziert. Es war möglich, durch viralen Gentransfer in diesen defizienten Haarzellen die Glutamatexozytose zu induzieren und sogar das Hörvermögen konnte teilweise wiederhergestellt werden. Interessanterweise hielt aber auch das nicht den Verlust von SGNs auf. In diesen Studien wurde die Anzahl der Bändersynapsen pro IHZ nicht untersucht. Allerdings zeigten sich Auffälligkeiten in elektronenmikroskopischen Aufnahmen. Die synaptischen Bänder wurden als dünn und verlängert im Gegensatz zu den üblicherweise runden präsynaptischen Bändern beschrieben (Seal et al. 2008, Akil et al. 2012). Als Grund für die Degeneration von Bändersynapsen und Spiralganglienneuronen wurde in diesen Arbeiten vermutet, dass evozierte synaptische Aktivität nicht für die Bildung der Bändersynapsen, wohl aber für ihren Erhalt und den der afferenten Nervenendigungen und Neuronen notwendig sei.

Hier beobachteten wir in Otof-Knockout-Mäusen, dass synaptische Bänder in normaler Anzahl gebildet wurden und dann, nach starker Reduktion auf 50\% der üblichen Anzahl, auf diesem Niveau verblieben. Diese Reduktion findet anscheinend zu der Zeit statt, in der das Hören einsetzt (Roux et al. 2006). Weiterhin scheint der Verlust der Bändersynapsen im Otof-Knockout kaum - oder nur mit sehr langer Latenz - den Verlust von SGNs zu bewirken. Die tonotope Verteilung dieses Verlusts entspricht nicht dem der synaptischen Bänder: SGN sind mit 48 Wochen basal am stärksten betroffen und apikale und mittlere Windungen mäßig reduziert, während die synaptischen Bänder über das gesamte Corti-Organ auf 5-7 pro Haarzelle reduziert sind, also im Vergleich zu der Verteilung von Bändersynapsen in Wildtypen apikal und basal am geringsten beeinträchtigt sind (Meyer et al. 2009). Die Degeneration von SGN findet eher an den Orten der IHZ Degeneration statt.

Der kausale und zeitliche Zusammenhang der Degeneration von IHZ und SGN ist vielfach diskutiert worden, s. Review von Perez und Bao 2011. In vielen Fällen wurde eine sekundäre Degeneration der Neuronen nach Verlust der IHZ vermutet, wie in alternden C57BL/6 Mäusen (White et al. 2000). Auch nach Carboplatin-Applikation, die IHZ relativ selektiv vernichtet, findet ein progressiver SGN-Verlust statt (Takeno et al. 1998). So wird vielfach als Grund dafür eine nutritive Versorgung der SGNs durch IHZ und ihre Stützzellen angenommen, z.B. Neurotrophin 3 scheint essentiell für den SGN-Erhalt zu sein (Stankovic et al. 2004, Ernfors et al. 1995). Jedoch wurde auch beobachtet, dass SGNs die IHZ nach deren Verlust um viele Monate überleben, etwa nach Lärmtrauma in jungem Alter (Kujawa und Liberman 2006) und Genmutationen, die den isolierten Verlust von IHZ bewirken (Zilberstein et al. 2012). Auch primäre SGN-Degeneration ohne vorhergehendes IHZ-Sterben wurde schon beobachtet, wie auch in den oben beschriebenen Vglut $3^{-/-}$- und $\alpha 1 D^{-/-}$-Mäusen. 
Die Abwesenheit von Otoferlin beeinflusst erst relativ spät und in geringem Ausmaß den Erhalt der Spiralganglienneurone - trotz erheblichem IHZ Verlust - was für den prominenten Einfluss der Stützzellen auf den SGN-Erhalt spricht. Möglicherweise ist das der Grund dafür, dass Kinder mit DFNB9 nach Kochlea-Implantat Versorgung ein sehr gutes Ergebnis zeigten (Rouillon et al. 2006). Falls der Erhalt von Bändersynapsen abhängig von der synaptischen Aktivität ist, steht zu vermuten, dass in den Otoferlin-Mutanten die geringe residuale Exozytose (Pangršič et al. 2010) den Erhalt von einigen Bändersynapsen ermöglicht. Es wäre interessant, diese verbleibenden Bändersynapsen und ihre afferenten Nervenfasern genauer zu charakterisieren, z. B. in ihrer Spontanaktivität und der Morphologie der Synapse.

\subsubsection{Degeneration von äußeren Haarzellen und Lärmempfindlichkeit}

In den Otof-Knockout-Mäusen beginnt zwischen 12 und 24 Wochen ein Amplitudenschwund der otoakustischen Emissionen, der sich von den Bereichen der hohen Frequenzen zu den tiefen Frequenzen auszubreitet, s. Abb 3.2. In den histologischen Präparaten der Corti-Organe sahen wir einen dazu passenden Verlust von $\ddot{A H Z, ~ d e r ~ e b e n f a l l s ~ v o n ~ b a s a l ~}$ voranschreitet und zwischen 24 und 48 Wochen auch apikal beginnt. Die mittleren Windungen bleiben am längsten intakt. Dieses Muster des Haarzellverlusts entspricht dem vielfach beschriebenen Verlauf der Haarzelldegeneration in C57BL/6-Mäusen (Kane et al. 2012, Hequembourg und Liberman 2001, Stamataki et al. 2006). Allerdings sind C57BL/6Haarzellen - wie hier auch die der Wildtyp Kontrollen - gewöhnlich erst später betroffen. Es sieht so aus als seien die ÄHZ der Otof-Knockout-Mäuse wesentlich früher von den üblichen Degenerationsprozessen betroffen. Der hier beobachtete Status der ÄHZ von 12 Monate alten Otof-Knockout-Mäusen scheint vergleichbar mit C57BL/6-Mäusen im Alter von 15-18 Monaten (Hequembourg und Liberman 2001, Kane et al. 2012).

Möglicherweise sind die ÄHZ der Otof-Knockout-Mäuse empfindlicher gegenüber bislang ungeklärten Einflüssen. Es ist unwahrscheinlich, dass die Degeneration auf den Mangel an Otoferlin zurückzuführen ist, da ÄHZ nur während ihrer Reifung bis zum 6. postnatalen Tag Otoferlin exprimieren und in adulten Tieren nur in apikalen ÄHZ Otoferlinexpression verbleibt (Roux et al. 2006, Engel et al. 2006). Weiterhin konnten wir in jungen Tieren normale DPOAE-Amplituden messen, und der Amplitudenverlust begann erst relativ spät, nach ca 12-24 Wochen, deutlicher in Erscheinung zu treten. Die Störung des Systems aus afferenter und efferenter Innervation der ÄHZ könnte einen Einfluss auf den Erhalt der 
ÄHZ haben. Aber ein derartiger Effekt wurde bis jetzt in der Literatur nicht beobachtet: Katzen, denen neonatal operativ das efferente Faserbündel aus dem medialen Olivenkern (MOC-Fasern) durchtrennt wurde, zeigten keinen auffälligen ÄHZ Verlust nach einem Jahr (Walsh et al. 1998). Bei alternden C57BL/6-Mäusen wurde eine starke Reduktion der Efferenzen beobachtet, aber keine Korrelation zwischen Efferenz- und Haarzellverlust (Fu et al. 2010).

Allerdings wurden mehrfach Hinweise darauf gefunden, dass der MOC-Reflexbogen (s. Kapitel 1.1 auf S.2) die Empfindlichkeit gegenüber Lärmtrauma beeinflusst, z. B. in Chinchillas (Zheng et al. 1997), Meerschweinchen (Reiter und Liberman 1995)und Mäusen (Maison et al. 2013). Maison et al. sahen nach einwöchiger akustischer Überstimulation mit $84 \mathrm{~dB}$ eine deutliche Neuropathie mit Reduktion der ABR-Welle I und Bändersynapsenverlust, sowie ÄHZ-Verlust in den Mäusen, deren MOC-Faserbündel vor der Exposition durchtrennt wurde. Die physiologische Rolle des MOC-Reflexes mag in der Verbesserung des SignalRausch-Verhältnisses liegen, ein darüber hinausgehender Schutz vor unphysiologischem Lärmtrauma bleibt dennoch umstritten, da in vielen Versuchen die Ergebnisse nicht eindeutig darauf verwiesen oder keinen Effekt des MOC-Reflexes zeigten (Christopher Kirk und Smith 2003, Liberman und Gao 1995).

In den hier beobachteten Otof-Knockout-Mäusen sollte aufgrund der angeborenen Taubheit nicht nur der MOC-Reflex komplett fehlen, sondern auch der Mittelohrreflex. Dieser reagiert auf tieffrequente laute Geräusche mit einer Aktivierung des Stapediusmuskels, der Zug auf den Stapes ausübt und so die Schallleitung schon im Mittelohr beeinflusst (Mukerji et al. 2010, Liberman und Guinan 1998). Wir konnten dennoch keine erhöhte Lärmempfindlichkeit der ÄHZ in den Otof-Knockout-Mäusen ausmachen. Möglicherweise liegt das an den Konditionen des hier verwendeten Lärmtraumas oder der Unterschied würde erst nach längerer Postexpositionszeit auffällig werden (Wang et al. 2002). Möglicherweise ist das Ausmaß der Protektion durch die efferente Innervation in adulten C57BL/6-Mäusen generell zu vernachlässigen.

Wir vermuten, dass es andere unbekannte Umweltfaktoren gibt oder auch genetische Faktoren, die in Zusammenhang mit der Otof Mutation zu einer aggravierten Degeneration der ÄHZ in Otof-Knockout-Mäusen führen. 


\subsection{Alterndes Gehör und das ahl-Allel}

Die hier verwendete Otof-Mauslinie basiert auf C57BL/6-Mäusen. Es ist bekannt, dass diese Tiere homozygot das rezessive ahl-Allel (age-related hearing loss) tragen (Johnson et al. 1997, Keithley et al. 2004), das mit einer Splice Variante des Cadherin 23 assoziiert ist (Noben-Trauth et al. 2003). Cadherin 23 ist involviert in Organisation von Stereozilienentwicklung (Di Palma et al. 2001) und bildet die Tip-Link-Struktur. Diese Mäuse sind einer frühen Altersschwerhörigkeit ausgesetzt (Mikaelian et al. 1974, Li und Borg 1991, White et al. 2000, Hequembourg und Liberman 2001, Kane et al. 2012). Sie werden vielfach als Modell für frühen, schnellprogrediente Hörverlust benutzt, da ein ähnliches Muster des sensorineuralen Hörverlusts auch bei Menschen mit Presbycusis beobachtet wurde (Schuknecht und Gacek 1993).

In der audiometrischen Evaluation dieser Mäuse sieht man ein kontinuierliches Ansteigen der Hörschwellen, das schon im Alter von 2-3 Monaten beginnt. Dabei sind die Schwellen über alle Testfrequenzen betroffen, betont aber in den hohen Frequenzen, wie wir hier beobachteten und beschrieben war (Li und Borg 1991, Park et al. 2010, Kane et al. 2012).Die otoakustischen Emissionen werden ebenfalls schwächer im Verlauf der Zeit, wir beobachteten hier ab 24 Wochen einen Amplitudenverlust in den hohen Testfrequenzen. Auch diese Ergebnisse sind vergleichbar mit früheren Untersuchungen (Martin et al. 2007, Park et al. 2010).

Der Verlust der DPOAE scheint dem sichtbaren Verlust von ÄHZ leicht vorauszueilen. Dieser beginnt am basalen Ende der Kochlea und setzt sich in Richtung apikal fort. Zeitlich versetzt wird auch ein apikaler Haarzellverlust sichtbar (Stamataki et al. 2006, Kane et al. 2012). Zahlreiche Vermutungen hinsichtlich der Hintergründe dieses Zellsterbens liegen vor, darunter die Hypothese, dass es sich um mitochondrial induzierte Apoptose handelt (Someya et al. 2009), die durch oxidativen Stress verursacht wird. Basale ÄHZ seien dem gegenüber empfindlicher als die apikalen (Sha et al. 2001). Andere Vermutungen besagen, dass die Cadherin 23 Mutation durch einen Defekt in den Stereozilien-Tip-Links zu chronischer Depolarisation führt, die den Haarzellen schadet (Johnson et al. 2010). Auch die IHZ sterben ab 48 Monaten nach und nach ab. Der Verlust schreitet von basal nach apikal fort. Die Spiralganglienneuronen bleiben in C57BL/6-Mäusen vergleichsweise lange erhalten. Im Alter von 12 Monaten konnten wir keinen markanten Unterschied in der Neuronendichte im Rosenthalkanal im Vergleich zu 2 Monate alten Tieren feststellen. Stamataki et al. 
kommen zu ähnlichen Ergebnissen (Stamataki et al. 2006, White et al. 2000), während andere Untersuchungen bei älteren Tieren eine signifikante Reduktion der SGN-Dichte beobachteten (Park et al. 2010, Someya et al. 2009, Hequembourg und Liberman 2001).

Zellverluste von Haarzellen und Spiralganglienneuronen erklären daher nicht die Hörschwellenverluste, die wesentlich früher beginnen und frequenzunspezifisch sind. Ison et al vermutete 2007 daher zwei verschiedene Formen von Degeneration: Eine, die sich auf die hohen Frequenzen fokussiert und somit mit basalem Verlust von ÄHZ und IHZ zu erklären ist und eine Weitere, die uniform und frequenzunspezifisch von jungem Alter an fortschreitet (Ison et al. 2007). Als Grund für diese letztere Form von Hörverlust wurden verschiedene Ursachen diskutiert, Hequembourg beobachtete 2001 eine früh beginnde Degeneration der Fibrozyten im Spiralligament und eine stetige Volumenabnahme der Stria vascularis. Allerdings konnte in nachfolgenden Untersuchungen trotz dieser morphologischen Veränderungen keine Veränderung des endokochleären Potentials basal oder apikal in C57BL/6-Mäusen gefunden (Lang et al. 2002), das diesen Hörverlust erklären könnte.

\subsubsection{Altersabhängige Synaptopathie der C57BL/6-Mauslinie}

White et al. beobachteten 2001 die Dendriten der bipolaren SGNs und stellten fest, dass die distalen Anteile sehr viel früher verschwinden als proximale Fasern oder Zellkörper (White et al. 2000). Stamataki et al. untersuchten dann 2006 in elektronenmikroskopischen Bildern direkt die afferenten Synapsen an den IHZ: Die afferenten Endigungen der SGNs waren in 12 Monate alten Tieren deutlich größer und auf der präsynaptischen Seite mit größeren Bändersynapsen mit mehr Vesikeln vergesellschaftet. Insgesamt hatte die Anzahl der Synapsen in den älteren Tieren jedoch deutlich abgenommen (Stamataki et al. 2006). Die Quantifikation der Bandsynapsen aus EM Daten von Stamataki et al. stimmt sehr genau mit unseren Resultaten überein. Bei 40-50\% Entfernung von basalem Ende eine Reduktion von 16,8 $\pm 2,4$ pro IHZ mit zwei Monaten auf 9,2 $\pm 3,1$ mit 12 Monaten; bei uns in ungefähr gleicher Entfernung von dem basalem Ende: von 17,7 $\pm 1,9$ auf 9,3 $\pm 3,9$ pro IHZ.

Es wird angenommen, dass diese Neurodegeneration durch Glutamat-Exzitotoxizität verursacht wird (Puel et al. 1994, 1998). Glutamatexzitotoxizität wurde nach Ischämie (Pujol et al. 1990) und nach Lärmtrauma beobachtet (Puel et al. 1998). Tatsächlich wurde schon mehrfach die Degeneration von Synapsen und afferenten Fasern nach Lärmtrauma beschrieben. Die der SGN folgte teils mit langer Latenz nach (Kujawa und Liberman 2006, 2009). 
Auch unsere Studie lässt auf den Einfluss von Glutamat-Exzitotoxizität auf Synapsenverlust schließen. Wir sahen nach leichtem Lärmtrauma eine basale Reduktion der synaptischen Bänder, die dem Bereich des Hörschwellenschwundes und DPOAE-Reduktion entsprach (s. Abb 3.12 auf S.37). Nach schwerem Lärmtrauma beobachteten wir eine stärker ausgeprägte Reduktion der synaptischen Bänder, die wiederum in den betroffenen Regionen des CortiOrgans auftrat. Gleichzeitig waren die Otof-Knockout-Mäuse, die keine stimulusabhängige Glutamatexozytose aufweisen, nicht von einem Verlust der Bändersynapsen betroffen. Interessanterweise zeigte der hier beobachtete Ablauf der altersabhängigen Degeneration des Innenohrs ein deutlich anderes Muster als in CBA/CAJ-Maus-Innenohren: Sergeyenko et al. untersuchte alternde Tiere dieser Mauslinie und beobachtete ab 16 Wochen postnatal einen progressiven Verlust von Bändersynapsen, der bis zur 96sten Woche apikal am stärksten ausgeprägt ist. Gleichzeitig kommt es zum Verlust von SGN, der auch bis zur 64sten Woche hauptsächlich apikale und mittlere Windung betrifft. IHZ- und ÄHZ-Anzahl sind erst ab 96 Wochen betroffen, wiederum zunächst von apikaler Degeneration. Es wird postuliert, dass diese Neuropathie wesentlich zum Hörverlust im Alter beiträgt (Sergeyenko et al. 2013). Auch unsere Ergebnisse zeigen eine früh beginnende, altersabhängige Synaptopathie, die dem Haarzellverlust vorausgeht. Wir vermuten, dass diese hauptsächlich verantwortlich für den altersabhängigen Hörschwellenschwund in den tiefen Frequenzen ist. Unsere Ergebnisse bestärken uns desweiteren in der Meinung, dass der genetische Hintergrund bei Mutantenlinien im Bezug auf IHZ-, ÄHZ- und SGN-Verlust zu beachten ist und die Wechselwirkungen zwischen den Auswirkungen der im Vordergrund stehenden Mutation und den Auswirkungen des genetischen Hintergrund schwer einzuschätzen sind. 


\section{Zusammenfassung}

Auditorische Synaptopathien verursachen sensorineurale Schwerhörigkeit unterschiedlicher Ausprägung. Es sind sowohl erworbene Formen bekannt, die durch Lärm oder altersbedingte Prozesse verursacht werden, als auch angeborene Formen, die zumeist genetische Ursachen haben. Eine Form der angeborenen Synaptopathie ist die rezessive, nichtsyndromale Taubheitsform DFNB9, die auf Genmutationen des Proteins Otoferlin beruht. Otoferlin ist ein Transmembranprotein, das essentiell für die stimulusabhängige Transmitterausschüttung an der Bändersynapse der IHZ im Innenohr ist. Um die Prognose von Patienten mit auditorischen Synaptopathien einschätzen zu können, ist es wichtig, den zeitlichen Verlauf und das Muster der neuronalen Degeneration zu kennen. Aufgrund des Fehlens von schützenden Reflexen - wie dem medialen olivocochleärem Reflex - könnte zusätzlich eine erhöhte Lärmempfindlichkeit bestehen, die einen frühen Verlust der Funktion der ÄHZ begünstigen würde.

Wir haben Otof-Knockout-Mäuse im Alter von 6 Tagen bis 48 Wochen untersucht und die Funktion des Corti-Organs mittels Hirnstammaudiometrie und Messung der otoakustischen Emissionen getestet. In immunhistochemischen Färbungen von Corti-Organ-Präparaten wurde weiterhin die Degeneration von IHZ und ÄHZ, Bändersynapsen und Spiralganglienneuronen beobachtet. Weiterhin wurden bei 2 Monate alten Otof-Knockout-Mäusen die Auswirkungen eines leichten oder schweren Lärmtraumas quantifiziert.

Wir beobachteten eine frühe und progrediente Degeneration des Innenohrs in den OtofKnockout-Tieren. Im Alter von 24 Wochen waren die Amplituden der otoakustischen Emissionen im Vergleich zu den Otof-Wildtyp-Kontrollen deutlich reduziert und dieser Verlust war mit 48 Wochen noch stärker ausgeprägt. Dazu passte der Verlust der ÄHZ, der ebenfalls in den Knockout-Mäusen gravierender war. Noch stärker war die mutationsabhängige Degeneration der IHZ ausgeprägt, die bei den Otof-Knockout-Tieren mit 48 Wochen über die gesamte Länge des Corti-Organs einen Verlust von $25-85 \%$ betrug, während in 
gleichaltrigen Wildtyp-Kontrollen nur basal 10-50\% degenerierten. Die Anzahl der Bändersynapsen waren in beiden Gruppen im Alter von 6 Tagen vergleichbar. Danach zeigten Otof-Knockout-Mäuse eine Reduktion auf 5-7 Bändersynapsen pro IHZ, die im weiteren Altersverlauf konstant blieb. Otof-Wildtyp-Mäuse zeigten dagegen einen altersabhängigen Verlust von Bändersynapsen, der erst ab 12 Wochen langsam fortschritt. Der altersabhängige Verlust von Spiralganglienneuronen schien in den Otof-Knockout-Tieren etwas stärker ausgeprägt.

Wir führten zwei unterschiedliche Lärmtrauma-Expositionsversuche durch. Im ersten wurden 6-8 Wochen alte Otof-Knockout-Mäuse gemeinsam mit ihren gesunden WildtypWurfgeschwistern für 15 min mit 103 dB 4-16 kHz Rauschen beschallt. Wir beobachteten eine gleichartige Reduktion der otoakustischen Emissionen in Knockout und Wildtyp und keinen Zellverlust. Die Bändersynapsen waren nur beim Wildtyp in den basalen Abschnitten der Kochlea, die für die hohen Frequenzen kodieren, reduziert. Im Zweiten Lärmtrauma wurden wiederum 6-8 Wochen alte Otof-Knockout-Mäuse und Kontrollen gleichzeitig beschallt, in diesem Fall mit 2 h von 120 dB 4-16 kHz Rauschen. Bei diesen Tieren waren die otoakustischen Emissionen in beiden Gruppen auf ein Minimum reduziert. Wir sahen bei beiden Gruppen einen deutlichen Verlust von ÄHZ in den basalen Abschnitten des Corti-Organs. Die Bändersynapsen der Wildtyp-Tiere waren über die gesamte Länge des Corti-Organs stark reduziert und die der Knockout-Mäuse nicht verändert, was zu der Theorie der Glutamat-Exzitotoxizität als Mechanismus der Lärmschädigung passt.

Hier wurden zum ersten Mal die altersabhängigen Veränderungen in Otof-Knockout-CortiOrganen beobachtet. Die Abwesenheit von Otoferlin scheint einen aggravierten Verlust von IHZ und ÄHZ im Alter zu bewirken, dessen Ursache unklar ist. Wir konnten keinen Anhalt dafür finden, dass dieser durch eine erhöhte Lärmempfindlichkeit zustande kommt. Die geringe Beeinflussung der Spiralganglienneuronenzahl und der Erhalt von Bändersynapsen lässt auf eine gute Prognose für die Implantatversorgung von Patienten mit dieser Synaptopathie schließen. 


\section{Anhang}

\section{Lösungen}

Morse-Lösung:

$10 \%$ Natriumcitrat

$22.5 \%$ Ameisensäure

Mowiol Mounting Medium:

Mowiol 4-88 (Carl Roth; 0713.1, 50 g)

Glycerol

Tris

DABCO (Carl Roth; 0718.1, 25 g)

\section{Formaldehydlösung:}

$0.4 \mathrm{~g}$ PFA in $5 \mathrm{ml} 240 \mathrm{mM}$ PB auflösen

$\mathrm{dH}_{2} \mathrm{O}$ auf $10 \mathrm{ml}$ hinzufügen

auf $\mathrm{pH} 7$ adjustieren mit $\mathrm{NaOH}(1 \mathrm{~N})$

GSDB: Ziegenserum Verdünnungspuffer $(60 \mathrm{ml})$ :

$10 \mathrm{ml}$ Ziegenserum

$1.8 \mathrm{ml} \mathrm{10 \%} \mathrm{Triton} \mathrm{X-100} \mathrm{(0.3 \% )}$

$5 \mathrm{ml} 240 \mathrm{mM}$ PB

$6.75 \mathrm{ml} 4 \mathrm{M} \mathrm{NaCl}$

$36.45 \mathrm{ml} \mathrm{dH}_{2} \mathrm{O}$

aliquotieren und bei -20 Grad Celsius aufbewahren

Waschpuffer:

$83 \mathrm{ml} 240 \mathrm{mM}$ PB

$30 \mathrm{ml} 10 \%$ Triton X-100

$112.5 \mathrm{ml} 4 \mathrm{M} \mathrm{NaCl}$

$\mathrm{dH}_{2} \mathrm{O}$ auf 11 auffüllen 


\section{Tabellenverzeichnis}

3.1 Zellzahlen der IHZ und ÄHZ im Altersverlauf . . . . . . . . . . . . . . 26

3.2 Bändersynapsen pro IHZ im Zeitverlauf . . . . . . . . . . . . . . . . 29

3.3 Zellzahlen der IHZ und ÄHZ nach Lärmtrauma . . . . . . . . . . . . . . 36

3.4 Bändersynapsen pro IHZ nach Lärmtrauma . . . . . . . . . . . . . 38 


\section{Abbildungsverzeichnis}

1.1 Akustisch evozierte Potentiale der Maus nach 80 dB Klick-Stimulus . . . . 4

2.1 Corti-Organ der Maus und Schema der tonotopen Repräsentation der Frequenzen ............................ 16

3.1 Hörschwellen und Amplituden in alternden Mäusen . . . . . . . . . . . . . 22

3.2 DPgramm in alternden Mäusen . . . . . . . . . . . . . . . 23

3.3 DPOAE-Amplituden bei F2: 11.3 und F2: $22.6 \ldots \ldots . \ldots . \ldots 23$

3.4 Degeneration der IHZ und ÄHZ von basal nach apikal . . . . . . . . . . 25

3.5 Innere Haarzellen und synaptische Bänder in alternden Mäusen . . . . . . . 27

3.6 Anzahl der synaptischen Bänder im Zeitverlauf . . . . . . . . . . . . . 28

3.7 Spiralganglienneurone im Zeitverlauf . . . . . . . . . . . . . 30

3.8 Hörschwellen und Amplituden nach Lärmtrauma . . . . . . . . . . . . . . 32

3.9 DPgramm nach Lärmtrauma . . . . . . . . . . . . . . . . . . . . . 32

3.10 Verlust von Haarzellen nach leichtem Lärmtrauma ． . . . . . . . . . . . . . 34

3.11 Verlust von Haarzellen nach schwerem Lärmtrauma . . . . . . . . . . . . . 35

3.12 Verlust von synaptischen Bändern nach Lärmtrauma . . . . . . . . . . . . 37 


\section{Literaturverzeichnis}

Akil O, Seal RP, Burke K, Wang C, Alemi A, During M, Edwards RH, Lustig LR (2012): Restoration of hearing in the VGLUT3 knockout mouse using virally mediated gene therapy. Neuron $\underline{75}, 283-293$

Beurg M, Michalski N, Safieddine S, Bouleau Y, Schneggenburger R, Chapman ER, Petit C, Dulon D (2010): Control of exocytosis by synaptotagmins and otoferlin in auditory hair cells. J Neurosci $\underline{30}, 13281-13290$

Bielefeld EC, Tanaka C, Chen G, Henderson D (2010): Age-related hearing loss: Is it a preventable condition? Hear Res 264, 98-107

Brandt A, Striessnig J, Moser T (2003): CaV1.3 channels are essential for development and presynaptic activity of cochlear inner hair cells. J Neurosci $\underline{23}, 10832-10840$

Brownell WE, Bader CR, Bertrand D, de Ribaupierre Y (1985): Evoked mechanical responses of isolated cochlear outer hair cells. Science 227, 194-196

Christopher Kirk E, Smith DW (2003): Protection from Acoustic Trauma Is Not a Primary Function of the Medial Olivocochlear Efferent System. J Assoc Res Otolayngol $\underline{4}, 445-465$

Corey DP (2006): What is the hair cell transduction channel? J Physiol 576, 23-28

Dallos P (1992): The active cochlea. J Neurosci $\underline{12}, 4575-4585$

Ding DL, Wang J, Salvi R, Henderson D, Hu B-H, McFadden SL, Mueller M (1999): Selective Loss of Inner Hair Cells and Type-I Ganglion Neurons in Carboplatin-Treated Chinchillas: Mechanisms of Damage and Protection. Ann N Y Acad Sci $\underline{884}, 152-170$

Duncker SV, Franz C, Kuhn S, Schulte U, Campanelli D, Brandt N, Hirt B, Fakler B, Blin N, Ruth P, et al. (2013): Otoferlin Couples to Clathrin-Mediated Endocytosis 
in Mature Cochlear Inner Hair Cells. J Neurosci 33, 9508-9519

Engel J, Braig C, Rüttiger L, Kuhn S, Zimmermann U, Blin N, Sausbier M, Kalbacher H, Münkner S, Rohbock K, et al. (2006): Two classes of outer hair cells along the tonotopic axis of the cochlea. J Neurosci 143, 837-849

Ernfors P, Van De Water T, Loring J, Jaenisch R (1995): Complementary roles of BDNF and NT-3 in vestibular and auditory development. Neuron $\underline{14}, 1153-1164$

Fu B, Le Prell C, Simmons D, Lei D, Schrader A, Chen AB, Bao J (2010): Age-related synaptic loss of the medial olivocochlear efferent innervation. Mol Neurodegener $\underline{5}, 53$

Gates GA, Mills JH (2005): Presbycusis. The Lancet 366, 1111-1120

Gates GA, Schmid P, Kujawa SG, Nam B, D’Agostino R (2000): Longitudinal threshold changes in older men with audiometric notches. Hear Res 141, 220-228

Gemeinsamer Bundesausschuss der Ärzte und Krankenkassen, Anlage 6. (2008): Richtlinien des Bundesausschusses der Ärzte und Krankenkassen über die Früherkennung von Krankheiten bei Kindern bis zur Vollendung des 6. Lebensjahres https://www.g-ba.de/downloads/62-492-506/RL_Kinder_2010-12-16.pdf [15.01.2015]

Gibson F, Walsh J, Mburu P, Varela A, Brown KA, Antonio M, Beisel KW, Steel KP, Brown SD (1995): A type VII myosin encoded by the mouse deafness gene shaker-1. Nature $\underline{374}, 62-64$

Glueckert R, Wietzorrek G, Kammen-Jolly K, Scholtz A, Stephan K, Striessnig J, Schrott-Fischer A (2003): Role of class D L-type Ca2+ channels for cochlear morphology. Hear Res 178, 95-105

Heidrych P, Zimmermann U, Bress A, Pusch CM, Ruth P, Pfister M, Knipper M, Blin N (2008): Rab8b GTPase, a protein transport regulator, is an interacting partner of otoferlin, defective in a human autosomal recessive deafness form. Hum Mol Genet $17,3814-3821$

Hequembourg S, Liberman MC (2001): Spiral Ligament Pathology: A Major Aspect of Age-Related Cochlear Degeneration in C57BL/6 Mice. J Assoc Res Otolaryngol $\underline{2}$, $118-129$ 
Holt JR, Pan B, Koussa MA, Asai Y (2014): TMC function in hair cell transduction. Hear Res

Ison JR, Allen PD, O’Neill WE (2007): Age-Related Hearing Loss in C57BL/6J Mice has both Frequency-Specific and Non-Frequency-Specific Components that Produce a Hyperacusis-Like Exaggeration of the Acoustic Startle Reflex. J Assoc Res Otolaryngol $\underline{8}, 539-550$

Jewett DL, Romano MN, Williston JS (1970): Human auditory evoked potentials: possible brain stem components detected on the scalp. Science $\underline{167}, 1517-1518$

Johnson KR, Erway LC, Cook SA, Willott JF, Zheng QY (1997): A major gene affecting age-related hearing loss in C57BL/6J mice. Hear Res 114, 83-92

Johnson KR, Yu H, Ding D, Jiang H, Gagnon LH, Salvi RJ (2010): Separate and combined effects of Sod1 and Cdh23 mutations on age-related hearing loss and cochlear pathology in C57BL/6J mice. Hear Res 268, 85-92

Kandel ER, Schwartz JH, Jessell TM (2000): Principles of Neural Science. Mcgraw-Hill Professional 4. Auflage, New York 2000

Kane KL, Longo-Guess CM, Gagnon LH, Ding D, Salvi RJ, Johnson KR (2012): Genetic background effects on age-related hearing loss associated with Cdh23 variants in mice. Hear Res $\underline{283}, 80-88$

Keithley EM, Canto C, Zheng QY, Fischel-Ghodsian N, Johnson KR (2004): Age-related hearing loss and the ahl locus in mice. Hear Res $\underline{188}, 21-28$

Kelsell DP, Dunlop J, Stevens HP, Lench NJ, Liang JN, Parry G, Mueller RF, Leigh IM (1997): Connexin 26 mutations in hereditary non-syndromic sensorineural deafness. Nature $\underline{387}, 80-83$

Kemp DT (1978): Stimulated acoustic emissions from within the human auditory system. J Acoust Soc Am 64, 1386-1391

Kemp DT (2002): Otoacoustic emissions, their origin in cochlear function, and use. $\mathrm{Br}$ Med Bull $\underline{63}$, 223-241

Kujawa SG, Liberman MC (2006): Acceleration of Age-Related Hearing Loss by Early Noise Exposure: Evidence of a Misspent Youth. J Neurosci 26, 2115-2123

Kujawa SG, Liberman MC (2009): Adding Insult to Injury: Cochlear Nerve Degeneration after „Temporary“ Noise-Induced Hearing Loss. J Neurosci 29, 14077-14085 
Lang H, Schulte BA, Schmiedt RA (2002): Endocochlear potentials and compound action potential recovery: functions in the C57BL/6J mouse. Hear Res $\underline{172}$, 118-126

Lauer AM, Fuchs PA, Ryugo DK, Francis HW (2012): Efferent synapses return to inner hair cells in the aging cochlea. Neurobiol Aging 33, 2892-2902

Li HS, Borg E (1991): Age-related loss of auditory sensitivity in two mouse genotypes. Acta Otolaryngol 111, 827-834

Liberman MC (1982): The cochlear frequency map for the cat: labeling auditory-nerve fibers of known characteristic frequency. J Acoust Soc Am 2ㅡ, 1441-1449

Liberman MC, Gao W-Y (1995): Chronic cochlear de-efferentation and susceptibility to permanent acoustic injury. Hear Res $\underline{90}, 158-168$

Liberman MC, Guinan JR. JJ (1998): Feedback control of the auditory periphery: Anti-masking effects of middle ear muscles vs. olivocochlear efferents. J Commun Disord 31, 471-483

Liberman MC, Gao J, He DZZ, Wu X, Jia S, Zuo J (2002): Prestin is required for electromotility of the outer hair cell and for the cochlear amplifier. Nature $\underline{419}$, 300-304

Maison SF, Usubuchi H, Liberman MC (2013): Efferent Feedback Minimizes Cochlear Neuropathy from Moderate Noise Exposure. J Neurosci $\underline{33}$, 5542-5552

Martin GK, Vazquez AE, Jimenez AM, Stagner BB, Howard MA, Lonsbury-Martin BL (2007): Comparison of distortion product otoacoustic emissions in 28 inbred strains of mice. Hear Res 234, 59-72

Marty NJ, Holman CL, Abdullah N, Johnson CP (2013): The C2 Domains of Otoferlin, Dysferlin, and Myoferlin Alter the Packing of Lipid Bilayers. Biochemistry, [14.08.2013]

Mathers C, Smith A, Marisol Concha: Global Burden of hearing loss in the Year 2000, http://www.who.int/healthinfo/statistics/bod_hearingloss.pdf [17.09.2013]

McLean WJ, Smith KA, Glowatzki E, Pyott SJ (2009): Distribution of the Na,K-ATPase alpha subunit in the rat spiral ganglion and organ of corti. J Assoc Res Otolaryngol $\underline{10}, 37-49$ 
Melcher JR, Guinan Jr JJ, Knudson IM, Kiang N (1996): Generators of the brainstem auditory evoked potential in cat. II. Correlating lesion sites with waveform changes. Hear res $\underline{93}, 28-51$

Meyer AC, Frank T, Khimich D, Hoch G, Riedel D, Chapochnikov NM, Yarin YM, Harke B, Hell SW, Egner A, Moser T (2009): Tuning of synapse number, structure and function in the cochlea. Nat Neurosci $\underline{12}, 444-453$

Mikaelian DO, Warfield D, Norris O (1974): Genetic progressive hearing loss in the C57-b16 mouse. Relation of behavioral responses to chochlear anatomy. Acta Otolaryngol $\underline{77}, 327-334$

Miller JM, Dolan DF, Raphael Y, Altschuler RA (1998): Interactive effects of aging with noise induced hearing loss. Scand Audiol Suppl $\underline{48}, 53-61$

Morse A (1945): Formic Acid-Sodium Citrate Decalcification and Butyl Alcohol Dehydration of Teeth and Bones for Sectioning in Paraffin. J Dent Res 24, 143153

Moser T, Predoehl F, Starr A (2013): Review of hair cell synapse defects in sensorineural hearing impairment. Otol Neurotol $\underline{34}, 995-1004$

Müller M, Hünerbein K von, Hoidis S, Smolders JWT (2005): A physiological placefrequency map of the cochlea in the CBA/J mouse. Hear Res 202, 63-73

Mukerji S, Windsor AM, Lee DJ (2010): Auditory Brainstem Circuits That Mediate the Middle Ear Muscle Reflex. Trends Amplif 14, 170-191

Nemzou N. RM, Bulankina AV, Khimich D, Giese A, Moser T (2006): Synaptic organization in cochlear inner hair cells deficient for the CaV1.3 ( $\alpha 1 \mathrm{D})$ subunit of L-type Ca2+ channels. J Neurosci 141, 1849-1860

Nickel R, Forge A (2008): Gap junctions and connexins in the inner ear: their roles in homeostasis and deafness: Curr Opin Otolaryngol Head Neck Surg $\underline{16}$, 452-457

Noben-Trauth K, Zheng QY, Johnson KR (2003): Association of cadherin 23 with polygenic inheritance and genetic modification of sensorineural hearing loss. Nat Genet $\underline{35}, 21-23$

Di Palma F, Holme RH, Bryda EC, Belyantseva IA, Pellegrino R, Kachar B, Steel KP, Noben-Trauth K (2001): Mutations in Cdh23, encoding a new type of cadherin, cause stereocilia disorganization in waltzer, the mouse model for Usher syndrome type 1D. Nat Genet 27, 103-107 
Pangršič T, Lasarow L, Reuter K, Takago H, Schwander M, Riedel D, Frank T, Tarantino LM, Bailey JS, Strenzke N, et al. (2010): Hearing requires otoferlin-dependent efficient replenishment of synaptic vesicles in hair cells. Nat Neurosci $\underline{13}, 869$ 876

Pangršič T, Reisinger E, Moser T (2012): Otoferlin: a multi-C2 domain protein essential for hearing. Trends Neurosci $\underline{35}, 671-680$

Park S-N, Back S-A, Park K-H, Kim D-K, Park SY, Oh J-H, Park YS, Yeo SW (2010): Comparison of Cochlear Morphology and Apoptosis in Mouse Models of Presbycusis. Clin Exp Otorhinolaryngol $\underline{3}, 126$

Perez P, Bao J (2011): Why do hair cells and spiral ganglion neurons in the cochlea die during aging? Aging Dis $\underline{2}, 231-241$

Petit C, Levilliers J, Hardelin J-P (2001): Molecular Genetics of Hearing Loss. Annu Rev Genet 35, 589-645

Puel JL, Pujol R, Tribillac F, Ladrech S, Eybalin M (1994): Excitatory amino acid antagonists protect cochlear auditory neurons from excitotoxicity. J Comp Neurol $\underline{341}, 241-256$

Puel JL, Ruel J, Gervais d'Aldin C, Pujol R (1998): Excitotoxicity and repair of cochlear synapses after noise-trauma induced hearing loss. Neuroreport $\underline{9}, 2109-2114$

Pujol R, Rebillard G, Puel JL, Lenoir M, Eybalin M, Recasens M (1990): Glutamate neurotoxicity in the cochlea: a possible consequence of ischaemic or anoxic conditions occurring in ageing. Acta Otolaryngol Suppl 476, 32-36

Ramakrishnan NA, Drescher MJ, Drescher DG (2008): Direct Interaction of Otoferlin with Syntaxin 1A, SNAP-25, and the L-type Voltage-gated Calcium Channel CaV1.3. J Biol Chem 284, 1364-1372

Reisinger E, Bresee C, Neef J, Nair R, Reuter K, Bulankina A, Nouvian R, Koch M, Bückers J, Kastrup L, et al. (2011): Probing the Functional Equivalence of Otoferlin and Synaptotagmin 1 in Exocytosis. J Neurosci 31, 4886-4895

Reiter ER, Liberman MC (1995): Efferent-mediated protection from acoustic overexposure: relation to slow effects of olivocochlear stimulation. J Neurophysiol $\underline{73}, 506-514$

Rodríguez-Ballesteros M, Reynoso R, Olarte M, Villamar M, Morera C, Santarelli R, Arslan E, Medá C, Curet C, Völter C, et al. (2008): A multicenter study on the 
prevalence and spectrum of mutations in the otoferlin gene (OTOF) in subjects with nonsyndromic hearing impairment and auditory neuropathy. Hum Mutat 29 , $823-831$

Rodríguez-Ballesteros M, Castillo D, J F, Martín Y, Moreno-Pelayo MA, Morera C, Prieto F, Marco J, Morant A, Gallo-Terán J, et al. (2003): Auditory neuropathy in patients carrying mutations in the otoferlin gene (OTOF). Hum Mutat $\underline{22}$, 451456

Rouillon I, Marcolla A, Roux I, Marlin S, Feldmann D, Couderc R, Jonard L, Petit C, Denoyelle F, Garabédian EN, Loundon N (2006): Results of cochlear implantation in two children with mutations in the OTOF gene. Int J Pediatr Otorhinolaryngol $\underline{70}, 689-696$

Roux I, Safieddine S, Nouvian R, Grati M, Simmler M-C, Bahloul A, Perfettini I, Le Gall M, Rostaing P, Hamard G, et al. (2006): Otoferlin, defective in a human deafness form, is essential for exocytosis at the auditory ribbon synapse. Cell $\underline{127}, 277-289$

Rutherford MA, Pangršič T (2012): Molecular anatomy and physiology of exocytosis in sensory hair cells. Cell Calcium $\underline{52}, 327-337$

Rybak LP, Ramkumar V (2007): Ototoxicity. Kidney Int 72, 931-935

Santarelli R, Del Castillo I, Rodríguez-Ballesteros M, Scimemi P, Cama E, Arslan E, Starr A (2009): Abnormal cochlear potentials from deaf patients with mutations in the otoferlin gene. J Assoc Res Otolaryngol 10, 545-556

Schmitz F, Königstorfer A, Südhof TC (2000): RIBEYE, a Component of Synaptic Ribbons: A Protein's Journey through Evolution Provides Insight into Synaptic Ribbon Function. Neuron $\underline{28}, 857-872$

Schug N, Braig C, Zimmermann U, Engel J, Winter H, Ruth P, Blin N, Pfister M, Kalbacher H, Knipper M (2006): Differential expression of otoferlin in brain, vestibular system, immature and mature cochlea of the rat. Eur J Neurosci 24, $3372-3380$

Schuknecht HF, Gacek MR (1993): Cochlear pathology in presbycusis. Ann Otol Rhinol Laryngol $\underline{102}, 1-16$

Schuknecht HF, Watanuki K, Takahashi T, Belal AA Jr, Kimura RS, Jones DD, Ota CY (1974): Atrophy of the stria vascularis, a common cause for hearing loss. Laryngoscope $\underline{84}, 1777-1821$ 
Seal RP, Akil O, Yi E, Weber CM, Grant L, Yoo J, Clause A, Kandler K, Noebels JL, Glowatzki E, et al. (2008): Sensorineural Deafness and Seizures in Mice Lacking Vesicular Glutamate Transporter 3. Neuron 57, 263-275

Sergeyenko Y, Lall K, Liberman MC, Kujawa SG (2013): Age-Related Cochlear Synaptopathy: An Early-Onset Contributor to Auditory Functional Decline. J Neurosci 33, 13686-13694

Sewell WF: Neurotransmitters and Synaptic Transmission; in: The Cochlea, 8.Auflage; hrsg. v. Dallos P, Popper AN, Fay RR; Springer New York 1996, 503-533, 9 [13.09.2013]

Sha SH, Taylor R, Forge A, Schacht J (2001): Differential vulnerability of basal and apical hair cells is based on intrinsic susceptibility to free radicals. Hear Res $\underline{155}$, $1-8$

Someya S, Xu J, Kondo K, Ding D, Salvi RJ, Yamasoba T, Rabinovitch PS, Weindruch R, Leeuwenburgh C, Tanokura M, Prolla TA (2009): Age-related hearing loss in C57BL/6J mice is mediated by Bak-dependent mitochondrial apoptosis. Proc Natl Acad Sci U S A 106, 19432-19437

Spatz WB, Löhle E (1995): Calcium-binding proteins in the spiral ganglion of the monkey, Callithrix jacchus. Hear Res $\underline{86}, 89-99$

Stamataki S, Francis HW, Lehar M, May BJ, Ryugo DK (2006): Synaptic alterations at inner hair cells precede spiral ganglion cell loss in aging $\mathrm{C} 57 \mathrm{BL} / 6 \mathrm{~J}$ mice. Hear Res $221,104-118$

Stankovic K, Rio C, Xia A, Sugawara M, Adams JC, Liberman MC, Corfas G (2004): Survival of Adult Spiral Ganglion Neurons Requires erbB Receptor Signaling in the Inner Ear. J Neurosci 24, 8651-8661

Strenzke N, Pauli-Magnus D, Meyer A, Brandt A, Maier H, Moser T (2008): Update zur Physiologie und Pathophysiologie des Innenohrs: Pathomechanismen der sensorineuralen Schwerhörigkeit. HNO $\underline{56}, 27-36$

Sun JC, Bohne BA, Harding GW (1994): Is the older ear more susceptible to noise damage? Laryngoscope 104, 1251-1258

Takeno S, Wake M, Mount RJ, Harrison RV (1998): Degeneration of spiral ganglion cells in the chinchilla after inner hair cell loss induced by carboplatin. Audiol Neurootol $\underline{3}, 281-290$ 
Tarnowski BI, Schmiedt RA, Hellstrom LI, Lee FS, Adams JC (1991): Age-related changes in cochleas of mongolian gerbils. Hear Res $\underline{54}, 123-134$

Varga R, Kelley P, Keats B, Starr A, Leal S, Cohn E, Kimberling W (2003): Non-syndromic recessive auditory neuropathy is the result of mutations in the otoferlin (OTOF) gene. J Med Genet $\underline{40}, 45-50$

Walsh EJ, McGee JA, McFadden SL, Liberman MC (1998): Long-term effects of sectioning the olivocochlear bundle in neonatal cats. J Neurosci $\underline{18}, 3859-3869$

Wang Y, Hirose K, Liberman MC (2002): Dynamics of Noise-Induced Cellular Injury and Repair in the Mouse Cochlea. J Assoc Res Otolaryngol $\underline{3}$, 248-268

White JA, Burgess BJ, Hall RD, Nadol JB (2000): Pattern of degeneration of the spiral ganglion cell and its processes in the C57BL/6J mouse. Hear Res $\underline{141}, 12-18$

WHO Estimates (2012): New estimates on the magnitude of disabling hearing loss http://www.who.int/pbd/deafness/estimates/en/index.html [28.06.2013]

Wong AB, Jing Z, Rutherford MA, Frank T, Strenzke N, Moser T (2013): Concurrent maturation of inner hair cell synaptic $\mathrm{Ca} 2+$ influx and auditory nerve spontaneous activity around hearing onset in mice. J Neurosci $\underline{33}$, 10661-10666

Yasunaga S, Grati M, Cohen-Salmon M, El-Amraoui A, Mustapha M, Salem N, El-Zir E, Loiselet J, Petit C (1999): A mutation in OTOF, encoding otoferlin, a FER-1-like protein, causes DFNB9, a nonsyndromic form of deafness. Nat genet $\underline{21}, 363-369$

Yasunaga S, Grati M, Chardenoux S, Smith TN, Friedman TB, Lalwani AK, Wilcox ER, Petit C (2000): OTOF Encodes Multiple Long and Short Isoforms: Genetic Evidence That the Long Ones Underlie Recessive Deafness DFNB9. Am J Hum Genet $\underline{67}, 591-600$

Zheng X-Y, Henderson D, Hu B-H, Ding D-L, McFadden SL (1997): The influence of the cochlear efferent system on chronic acoustic trauma. Hear Res 107, 147-159

Zilberstein Y, Liberman MC, Corfas G (2012): Inner hair cells are not required for survival of spiral ganglion neurons in the adult cochlea. J Neurosci $\underline{32}, 405-410$ 


\section{Danksagung}

An erster Stelle möchte ich Nicola Strenzke für ihre hervorragende Betreuung, ihre ständige Hilfe und ihr Engagement danken.

Dieses Projekt hat mir im Innenohrlabor einen Einblick in das wissenschaftliche Arbeiten ermöglicht und ich bin Tobias Moser und Nicola Strenzke zu großem Dank verpflichtet, dass ich Teil der Arbeitsgruppe werden durfte.

Besonders danken möchte ich Andrea Adden für die engagierte Mitarbeit während ihres Masterarbeitsprojektes. Es war sehr hilfreich und interessant das Projekt eine Zeit lang zusammen zu bearbeiten und zu diskutieren.

Zuletzt kann ich dem Innenohrlabor mit allen Mitgliedern nicht genug für die tolle Arbeitsatmosphäre danken, für unzählige fruchtbare Diskussionen, Anregungen und die Hilfe, die ich dort erhalten habe. 